\title{
Factor Investment: Evaluating Persistence Effect for Investment Performance and Sustainability Exposure
}

\author{
Xiaoshuang Yang ${ }^{1}$, Xingyu $\mathrm{Chen}^{2} \&$ Jiaxin Xie $^{3}$ \\ ${ }^{1}$ Coventry Business School, Coventry Univeristy, Coventry, UK \\ ${ }^{2}$ Fenglong (Shanghai) International Trading Co., Ltd., China \\ ${ }^{3}$ Goldsmiths, University of London, UK \\ Correspondence: Xiaoshuang Yang, Coventry Business School, Coventry Univeristy, Coventry, UK. E-mail: \\ sheansyong@gmail.com
}

Received: April 8, 2021

Accepted: May 23, 2021

Online Published: May 28, 2021

doi:10.5539/ijef.v13n6p143

URL: https://doi.org/10.5539/ijef.v13n6p143

\begin{abstract}
This research includes two separate studies. The first study is devoted to evaluating the persistence effect by analyzing performances of portfolios ranked based on previous performances under various factor models. The result shows that the shorter the holding period, the stronger the predictability and that the Multi-factor model has the highest explaining power for the excess return regarding the underlying factors. The second study is devoted to exploring how sustainable investing influences alpha by introducing a new sustainable factor to reflect the premium due to exposure to sin industries. The study result shows that there is no significant alpha associated with sustainable investing and that there is no significant return differential between funds that have high/low exposure to the sustainable factor.
\end{abstract}

Keywords: asset pricing, ESG, factor investment, green finance, persistence effect, sustainable investment

\section{Introduction}

This research is comprised of two separate studies. The first study is devoted to detecting the persistence effect. This study conducts an empirical analysis by first constructing rank portfolios of mutual funds based on previous performances and then evaluating their performance and the persistence effect under various factor models. The result shows that the shorter the holding period, the stronger the predictability. Besides, the Multi-factor model has the highest explaining power for the excess return regarding the underlying factors.

The second study is devoted to exploring how sustainable investing influences alpha. In this study, I constructed a new sustainable factor to reflect the premium due to exposure to sin industries. Then I performed a 4-step Fama-Macbeth analysis based on the mutual fund database 'fund_data_largest_500.csv' by using this factor. This research is devoted to exploring whether there is significant alpha associated with sustainable investing and whether there is a significant return differential between funds with high/low exposure to the sustainable factor according to the Fama-Macbeth results. The study result shows that there is no significant alpha associated with sustainable investing and that there is no significant return differential between funds that have high/low exposure to the sustainable factor.

The whole research is conducted by Python programming language. An Intel Core i5-8250U CPU (1.60 GHz) laptop with 8 GB RAM is applied for carrying out all the calculations and analyses. The Python codes and the task-based database are available on the Github link XUAN-FENG9/AFM_Mutual-Fund-Analysis (github.com).

This paper develops in the following outline. Following Section 2 first briefly summarizes the literature of studies about the persistence effect and sustainable investing. Following that, Section 3 describes the methodology and the construction of models. Then this paper moves into the main analysis - Section 4 illustrates the steps of the empirical studies and discusses the analysis results. The final Section 5 evaluates the whole task, summarizes major conclusions, and presents insights into further researches.

\section{Literature Review}

2.1 Persistence Effect

Hendricks et al. (1993) and Elton et al. (1996)'s study analyzed the return differential between the top and 
bottom decile funds, and they found a high level of persistence in the performance of mutual funds. However, Carhart (1997) includes the equity momentum (WML) as a fourth factor and concludes that persistence does not exist. Huij et al. (2007) mentioned that the model of Carhart (1997) might lead to a serious underestimation of the persistence effect. This is because sorting the mutual funds based on their performance in the last year can lead to high (low) beta funds appear at the top (down) decile when the market return is positive, and low (high) beta funds appear at the down (top) decile when the market return is negative. But the WML momentum factor will also present the same pattern - high (low) beta stocks appear at the top (down) decile when the market return is positive, and vice versa - simultaneously. Therefore, the alpha caused by persistence is absorbed in the WML factor, and the Carhart model shows that the outperformance disappears for mutual funds in high-ranked deciles. Berk (2005) argued that persistence could not exist in the long term if fund managers' skills are heterogeneous. And Bollen and Busse (2005) found that the persistence effect exists in the short term by analyzing high-frequency daily data.

\subsection{Sustainable Investing}

Environment, social, and governance issues are increasingly influencing financial activities and decisions worldwide. For example, the extent of the environmental impact of climate change is still uncertain, but the recent scientific evidence is increasingly worrisome and most governments are taking decisive steps in order to avert a catastrophe. The transition towards a low-carbon economy requires various financial tools and techniques that will have far-reaching implications for financial institutions, corporations, and investors. The ESG topic is also located in the area of impact investing, which focuses more on the intention to shift the future of the world. Impact investors proactively use their investments to generate a tangible, beneficial social or environmental impact alongside a financial return. For family foundations specifically, impact investing contributes to advance the core social and environmental goals while maintain or growing the overall endowment.

Many researchers have investigated whether investors can obtain superior risk-adjusted returns by implementing responsible investing strategies. Friede et al. (2015) found a positive association between a company's environmental, social, and governance (ESG) performance and its financial performance. However, there may be a publication bias, and the impact of ESG on stock returns depends on the extent to which climate risk and other ESG aspects are priced on the stock market. Hong and Kacperczyk (2009) find that "sin stocks" yield higher returns, while Hong et al. (2018) suggests that the pricing of ESG risks is incomplete. A recent study estimates the carbon premium across the world (Bolton \& Kacperczyk, 2020). There are also many other scholars who studied the various financial instruments and techniques applied in the context of ESG issues, such as the evolving climate policies. For example, how to use capital markets to create emissions trading systems and fundamental investing (Cremers \& Pareek, 2016; Schoenmaker \& Schramade, 2019; Van Nieuwerburgh \& Veldkamp, 2010).

It is also worthful to notice that the proxy used to represent the ESG level or rating varies across different rating agencies. This variation or disagreement on the ESG rating among different agencies may also influence the cross-section stock returns. In a 2021 working paper, Rajna Gibson, Philipp Krüger, and Peter Schmidt ("ESG Rating Disagreement and Stock Returns") study this influence by regressing the return on the independent variable called "Disp" (for "rating dispersion") - which is defined as the standard deviation across the ESG ratings for a particular firm in a particular year stemming from 7 different ESG databases - and a set of other controlling variables. Their results show that the coefficient on Disp is positively and statistically significant around the 5\% level, a result suggesting that the stocks of firms with high ESG rating disagreement tend to have higher returns going forward than the stocks of firms with low ESG rating disagreement. The "high ESG rating disagreement premium" may be explained by the risk brought by the disagreement - investors with ESG preferences tend to ask for a higher return to compensate for the uncertainty about the ESG rating.

In this research, I am devoted to testing whether greater exposure on "sin stocks" can yield higher returns, as Hong and Kacperczyk (2009) concluded, and whether there is significant alpha associated with sustainable investing.

\section{Methodology and Data}

\subsection{Study for Persistence Effect}

This research analyzes the mutual fund performance and persistence based on the database of the largest 500 funds (the 'fund_data_largest_500.csv' database) through time. The first step is to summarize the funds' data and load the Fama French database. Figure 1 plots the asset value over time. Figure 2 presents the cumulative log returns over time for each factor in the Fama-French database. Then, this research evaluates the performance and the persistence effect based on the decile portfolio constructed using 60- and 36-month formation periods and 
12-month holding periods. The models I used include CAPM model (Equation 1), Fama-French 3 factor model (Equation 2), and Carhart 4 factor model (Equation 3).

$$
\begin{gathered}
\text { Actual Return }=\alpha+R_{F}+\beta_{M k t} M k t-R F+\varepsilon \\
\text { Actual Return }=\alpha+R_{F}+\beta_{M k t} M k t-R F+\beta_{S M B} S M B+\beta_{H M L} H M L+\varepsilon \\
\text { Actual Return }=\alpha+R_{F}+\beta_{M k t} M k t-R F+\beta_{S M B} S M B+\beta_{H M L} H M L+\beta_{W M L} W M L+\varepsilon
\end{gathered}
$$

Where the $M k t-R F$ represents the stock market premium, the $S M B$ represents the size premium (small minus big), the $H M L$ represents the value premium (mature stocks minus growth stocks), and the $W M L$ represents the momentum factor (win minus lose). $\alpha$ represents the abnormal return/excess return that is not expected.

For each model, I set the holding periods as 12-months but set the formation period as 60 and 36-months separately. Therefore, there are 6 models. Finally, I investigate short-run performance persistence as documented by Berk and Green (2005) and Bollen and Busse (2005) based on the Fama-French 3 factor model by constructing another 6 models - rank portfolios 12- and 3-month formation periods and 12-, 3- and 1-month holding periods. The results are detailed in Appendix 1.

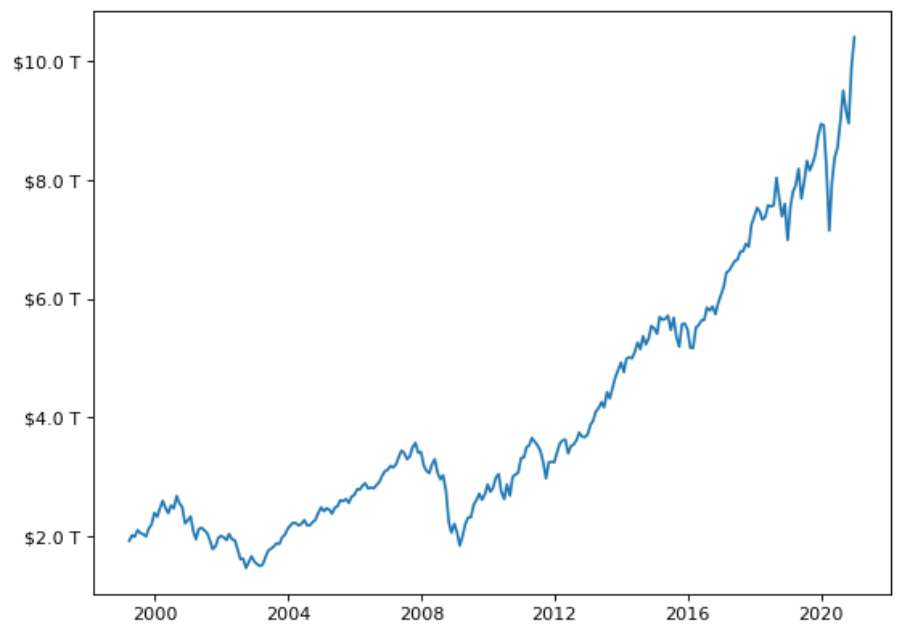

Figure 1. Asset over time of the largest 500 fund

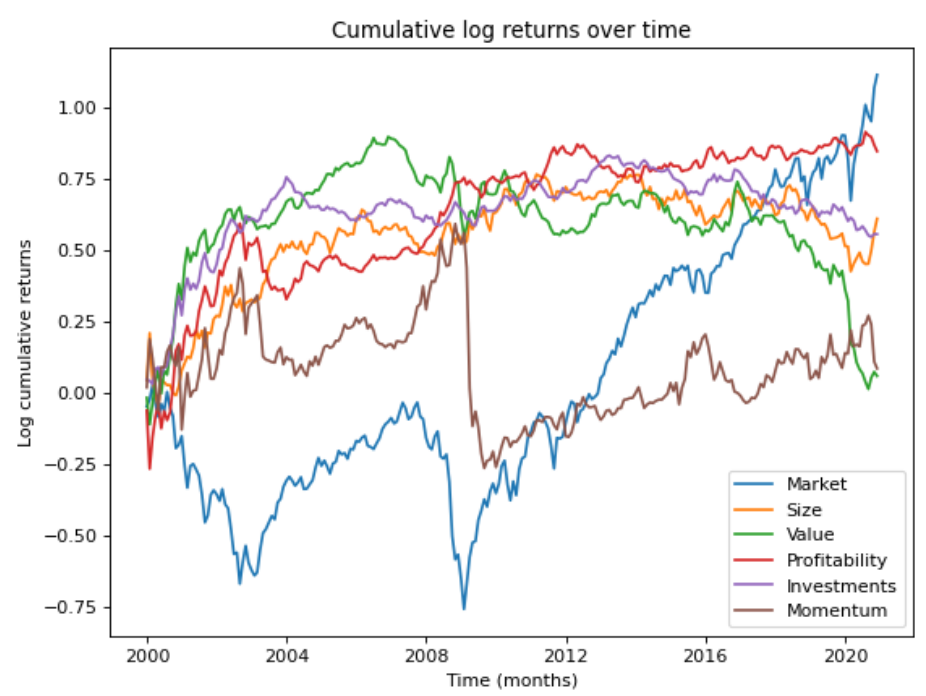

Figure 2. Cumulative log returns over time for Fama-French factors

\subsection{Study for Sustainable Investing}

This research firstly constructed a sin-premium factor to measure funds' exposure to the sin industry, then conducted a 4-step Fama-Macbeth analysis. 
The sin-premium factor is constructed through two steps. The first step is calculating the arithmetic average of monthly stock returns of all stocks in three sin industries: tobacco industry (SIC code: 211, 212, 213, and 214), alcohol industry (SIC code: 2082-2085), and oil \& gas industry (SIC code: 131, 132, 138). All the stock returns are collected on the WRDS database (WRDS - CRSP - Annual Update - Stock / Security Files - CRSP Monthly Stock) and set the period from July 1963 to December 2020. The original data and the after-aggregate monthly main data are available at the "sin industry.xlsx" document on https://github.com/XUAN-FENG9/AFM_assignment. The second step is to calculate the monthly sin-industry premium by subtracting the risk-free rate from the average sin-industry return defined in step 1. In this study, I defined this sin-industry premium as another factor - Sin-RF - and added it to the Fama-French data, as shown in Figure 3. The whole Fama-French data is available at the "FF.xlsx" document on https://github.com/XUAN-FENG9/AFM_assignment.

\begin{tabular}{rrrrrrrrr} 
& Mkt-RF & SMB & HML & RMW & CMA & Sin-RF & RF & WML \\
Date & & & & & & & & \\
\hline 196307 & -0.0039 & -0.0045 & -0.0094 & 0.0066 & -0.0115 & 0.0214 & 0.0027 & 0.0100 \\
196308 & 0.0507 & -0.0082 & 0.0182 & 0.0040 & -0.0040 & 0.0662 & 0.0025 & 0.0103 \\
196309 & -0.0157 & -0.0048 & 0.0017 & -0.0076 & 0.0024 & 0.0085 & 0.0027 & 0.0016 \\
196310 & 0.0253 & -0.0130 & -0.0004 & 0.0275 & -0.0224 & -0.0087 & 0.0029 & 0.0314 \\
196311 & -0.0085 & -0.0085 & 0.0170 & -0.0045 & 0.0222 & -0.0096 & 0.0027 & -0.0075 \\
$\ldots$ & $\ldots$ & $\ldots$ & $\ldots$ & $\cdots$ & $\cdots$ & $\ldots$ & $\cdots$ & $\ldots$ \\
202008 & 0.0763 & -0.0094 & -0.0294 & 0.0427 & -0.0144 & -0.0004 & 0.0001 & 0.0051 \\
$\mathbf{2 0 2 0 0 9}$ & -0.0363 & 0.0007 & -0.0251 & -0.0115 & -0.0177 & -0.1418 & 0.0001 & 0.0305 \\
$\mathbf{2 0 2 0 1 0}$ & -0.0210 & 0.0476 & 0.0403 & -0.0060 & -0.0053 & -0.0120 & 0.0001 & -0.0303 \\
$\mathbf{2 0 2 0 1 1}$ & 0.1247 & 0.0675 & 0.0211 & -0.0278 & 0.0105 & 0.3577 & 0.0001 & -0.1225 \\
202012 & 0.0463 & 0.0474 & -0.0146 & -0.0216 & -0.0008 & 0.1139 & 0.0001 & -0.0234
\end{tabular}

Figure 3. Fama-French data with the sin-RF factor

Following Figure 4 presents the cumulative log-returns of the 7 factors in the Fama-French data since 2000. We can see that for the sin premium factor, the cumulative return is always positive and is significantly higher than returns of all other factors from 2004 to 2016. This is in line with Hong and Kacperczyk (2009)'s result that stocks in sin industries can yield higher returns.

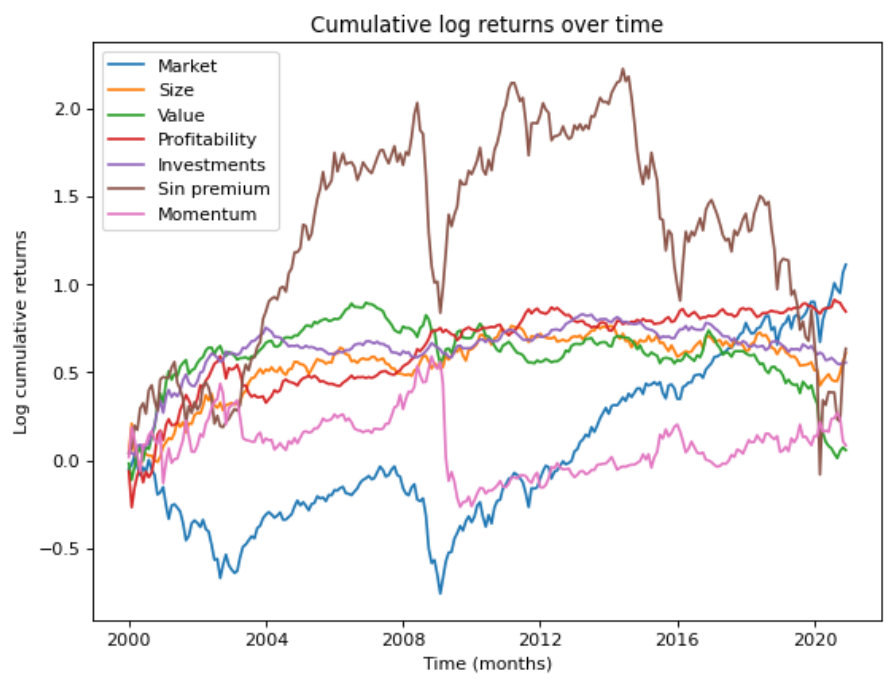

Figure 4. Fama-French cumulative return plot (after 2000)

After adding the Sin-RF factor to the Carhart-4 factor model, the adjusted model used for this analysis is presented in Equation (4).

$$
\begin{gathered}
\text { Actual Return }=\alpha+R_{F}+\beta_{M k t} M k t-R F+\beta_{S M B} S M B \\
+\beta_{H M L} H M L+\beta_{W M L} W M L+\beta_{S i n-R F} \operatorname{Sin}-R F+\varepsilon
\end{gathered}
$$


Where the $\operatorname{Sin}-R F$ factor represents the sin-industry premium (average return of companies in the sin industry minus the risk-free rate).

\section{Empirical Analysis}

\subsection{Performance Persistence Effect (Long-Term)}

The 36-months and 60-months lookback periods' cumulative return over the 12-months holding periods are presented in Figure 5 and Figure 6 separately. From the figures, we can see that the shorter lookback period leads to more accurate predictability. For example, the return of funds in the quantile 10 is significantly higher than others when using 36-months lookback period, but it is intertwined with the return of quantile 9 when using 60-months (longer) lookback period.

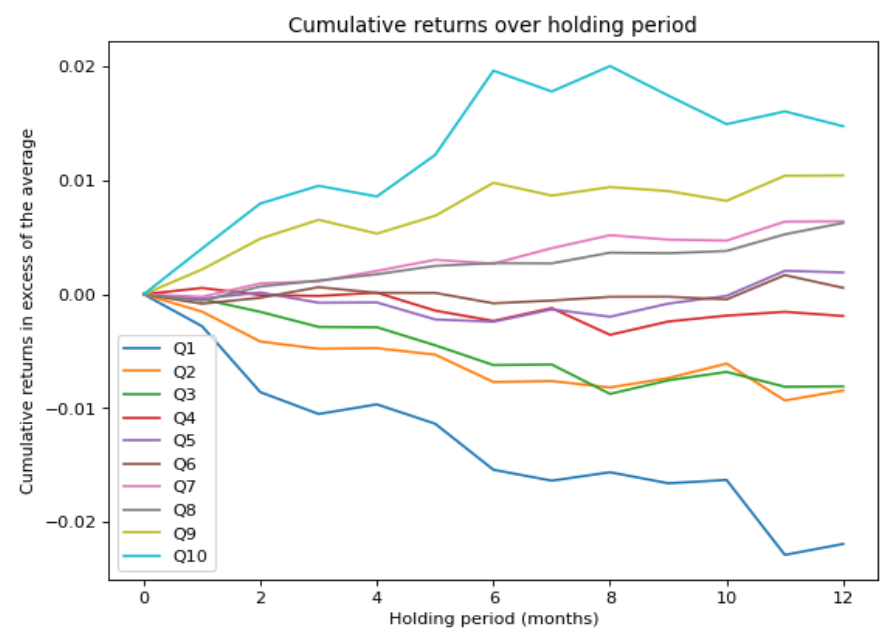

Figure 5. Cumulative returns over holding period based on 36-months lookback

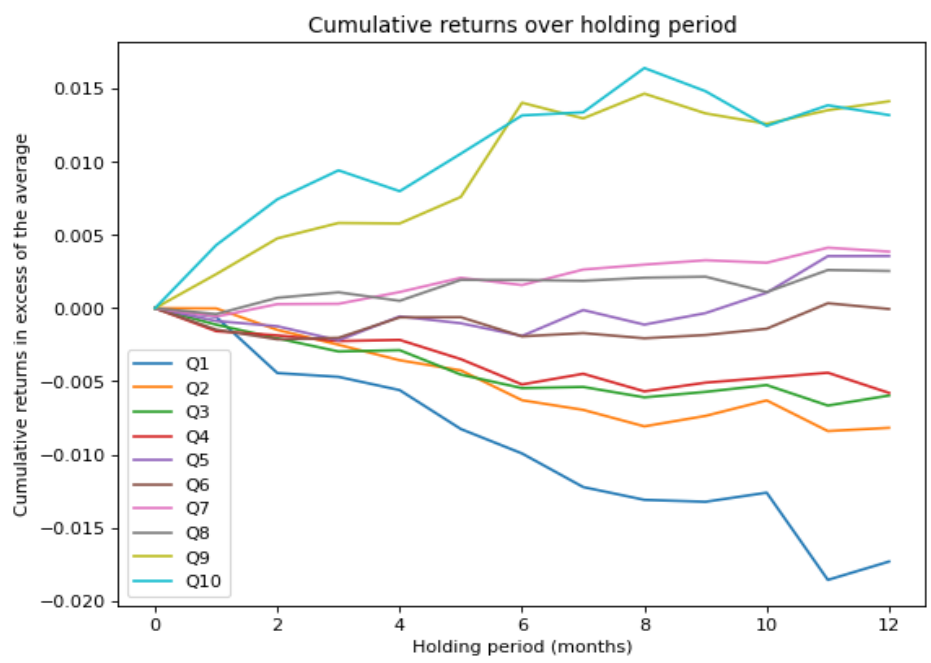

Figure 6. Cumulative returns over holding period based on 60-months lookback

Figure 7 summarizes the performance of quantile funds using three models - CAPM, FF-3 factors model, and the Carhart model - based on 36 and 60-months lookback periods. The detailed results are also available in Appendix 1. The results show that using the CAPM model leads to the strongest predictability for alpha. The other two models do not show significant persistence. This may be because the momentum factor in the Carhart model has already absorbed part of the persistence effect, and the HML and SMB factors are inherently conflicted - for example, small-cap stocks usually have a low book-to-market ratio. 


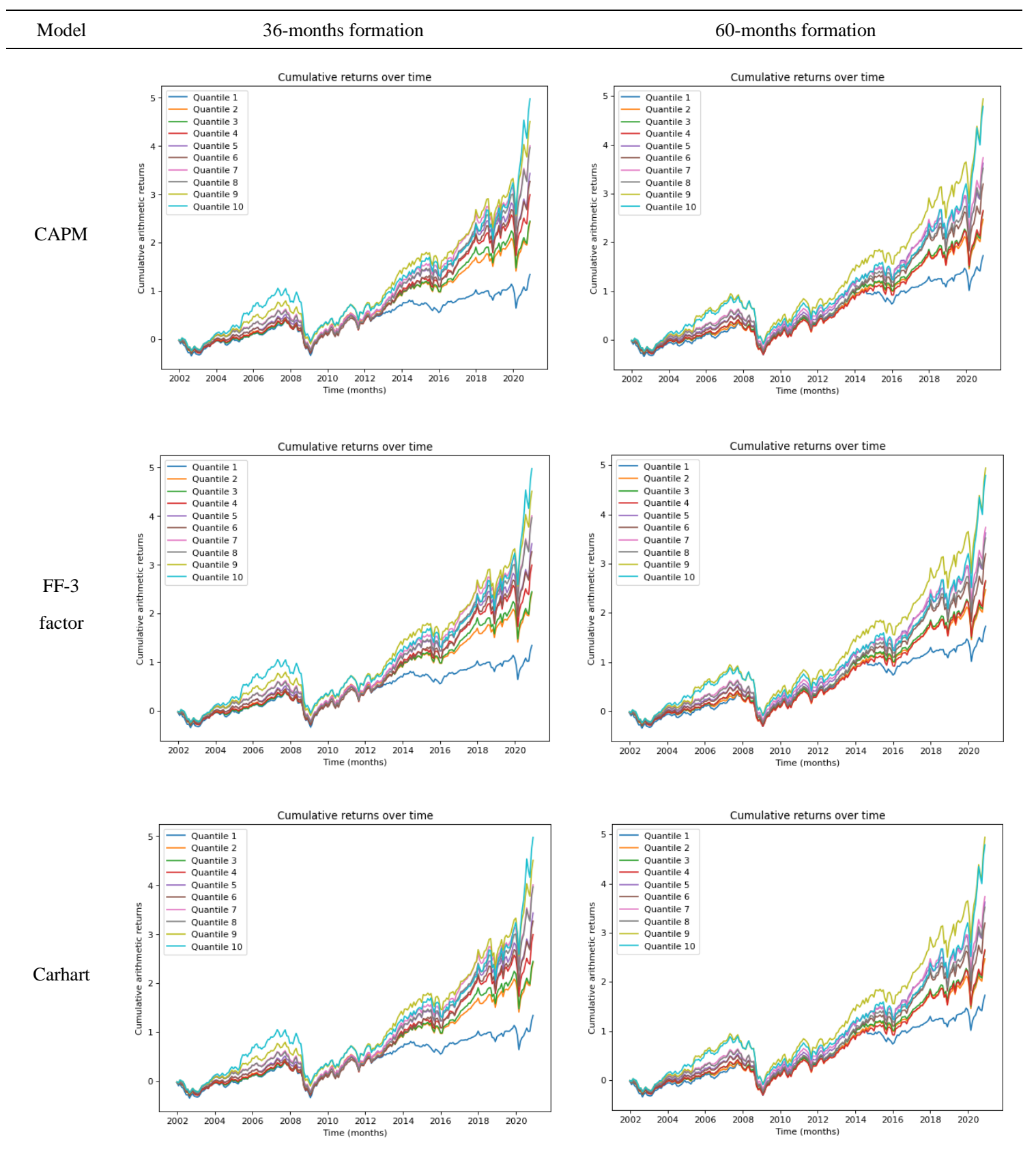

Figure 7. Quantile performance in holding periods under three models

Then I use the Fama-French 3 factor model to conduct the short-term persistence analysis. The result is presented in Figure 8, and the detail is available in Appendix 1. 


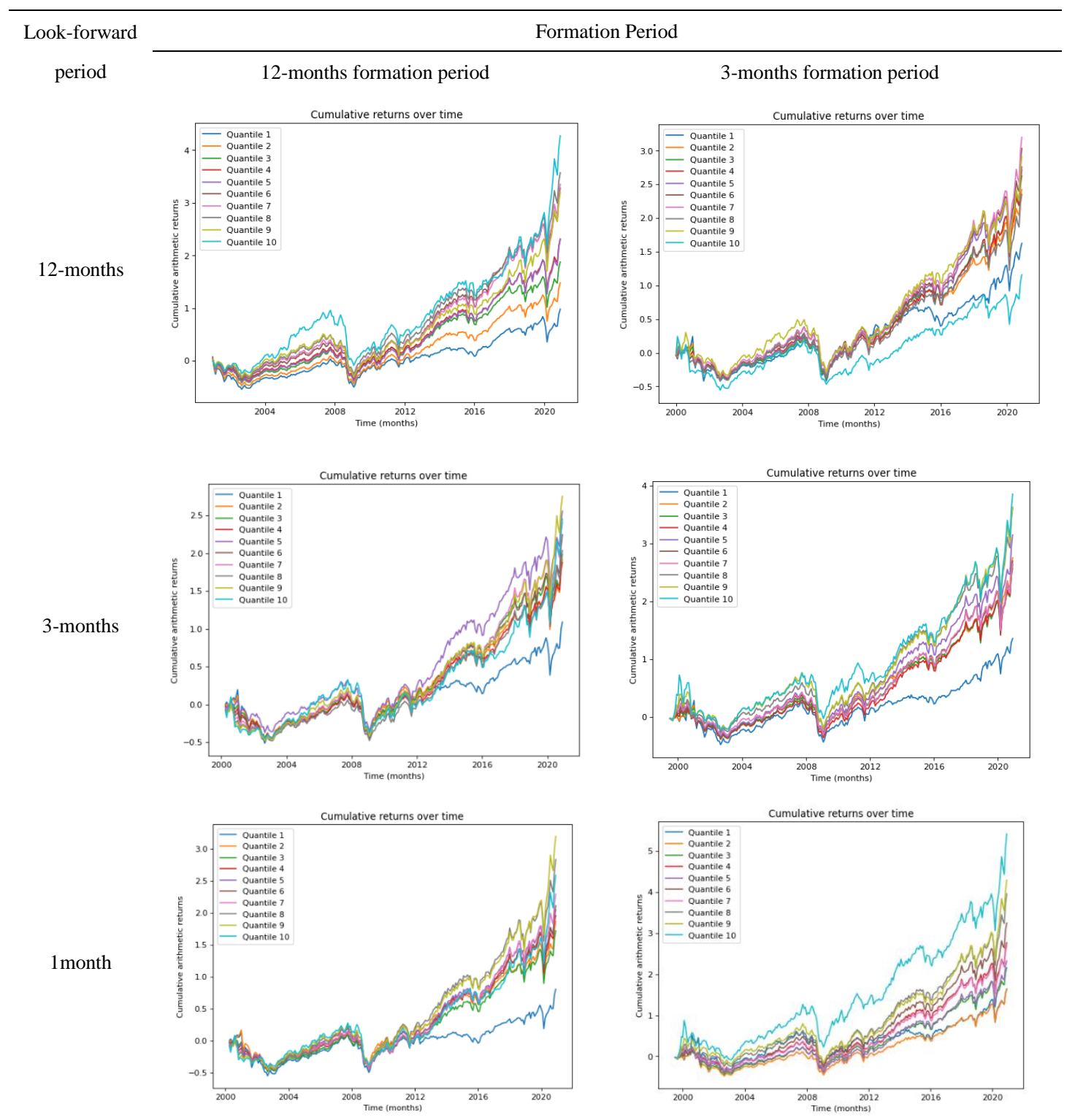

Figure 8. Quantile performance and persistence for short-term analysis (FF-3 model)

Based on the 12-months and 3-months formation period and the 12-, 3-, and 1- month(s) holding period, the predictability is the strongest for the 12-months formation - 12-months look-forward combination and the 3-months formation - 1-month look-forward combination. This can be explained that the average return of the longer past can not predict the shorter near future. If we take the 12-months as the formation period, the average return of the past 12 months may include longer-past influence that may not appear in the nearly 1 or 3-months, so the 3 and 1-months look-forward period have less predictability. But the same length look-forward period 12-months - appears to have a stronger persistence effect. The 3-months formation period is inherent a short period, so the strongest persistence effect appears when looking forward 1-month.

Furthermore, both the long-term and short-term analysis also shows that the top decile of funds does not always earn a statistically significant superior return, but the superior return between high and low deciles is significant.

\subsection{Performance Persistence Effect (Short-Term)}

Focusing on the short-term performance persistence, I set formation (12 and 3-months) and holding periods (12-, 3-, and 1-months), and I conduct my analysis based on the CAPM, FF-3 factor model, 4-factor Carhart model, FF-5 factors model (Equation 5, including profitability and investment quality factors), and a multifactor model (Equation 6) including all factors used in the previous models. Moreover, I conducted a separate analysis of a lag between formation and holding period of 1-month. 


$$
\begin{gathered}
\text { Actual Return }=\alpha+R_{F}+\beta_{M k t} M k t-R F+\beta_{S M B} S M B+\beta_{H M L} H M L+\beta_{R M W} R M W+\beta_{C M A} C M A+\varepsilon \\
\text { Actual Return }=\alpha+R_{F}+\beta_{M k t} M k t-R F+\beta_{S M B} S M B \\
+\beta_{H M L} H M L+\beta_{R M W} R M W+\beta_{C M A} C M A+\beta_{W M L} W M L+\varepsilon
\end{gathered}
$$

Where the $R M W$ factor is the return spread between profitable and unprofitable companies, and the $C M A$ factor represents the return spread between companies that invest conversely and companies that invest aggressively. The $M k t-R F$ represents the stock market premium, the $S M B$ represents the size premium (small minus big), the $H M L$ represents the value premium (mature stocks minus growth stocks), and the $W M L$ represents the momentum factor (win minus lose). $\alpha$ represents the abnormal return/excess return that is not expected.

This analysis is devoted to comparing the model difference on the short-term performance persistence. The result is presented in Appendix 2. From the result, we can see that based on the 3-and 12-months formation period, the shorter the holding period, the stronger the predictability, and that the multi-factor model has the highest explaining power for the excess return regarding the underlying factors. We also find that the top decile of funds does not earn a statistically significant superior return. Some of the other decile funds earn, on the contrary, a higher superior return compared to the top decile. This finding is in line with the finding of core analysis.

Furthermore, by constructing a lag of 1-month under the Fama-French 5 factor model and setting the 12-months formation - 1-month holding period, I found that the lag of 1-month has a great impact on the top 3 decile funds that have overperformances. The results are presented in Figure 9 and Figure 10.

Based on Fama-French 5 factor model,

12 month formation period and 1 month holding period,

the final results are (all numbers annualized):

\begin{tabular}{rrrrrrrrrrr} 
& Q1 & Q2 & Q3 & Q4 & Q5 & Q6 & Q7 & Q8 & Q9 & Q10 \\
\hline Avg returns & 0.0575149 & 0.0688206 & 0.0784184 & 0.0728707 & 0.0727581 & 0.0759005 & 0.0809365 & 0.0962108 & 0.0978525 & 0.111804 \\
Avg excess returns & 0.0344586 & 0.0457642 & 0.055362 & 0.0498144 & 0.0497017 & 0.0528442 & 0.0578801 & 0.0731545 & 0.0747961 & 0.0887474 \\
Volatility & 0.182539 & 0.15953 & 0.16085 & 0.154136 & 0.15391 & 0.154705 & 0.158186 & 0.168053 & 0.172692 & 0.195796 \\
Sharpe ratio & 0.188773 & 0.286869 & 0.344184 & 0.323184 & 0.322926 & 0.34158 & 0.3659 & 0.435306 & 0.433119 & 0.453264 \\
Alpha & -0.012305 & -0.00656777 & -0.0048749 & -0.00758558 & -0.0109685 & -0.00860109 & -0.00541525 & 0.00490758 & 0.00976862 & 0.014119 \\
Std. error (a) & 0.00151128 & 0.000926698 & 0.000811752 & 0.000520373 & 0.000376352 & 0.000352162 & 0.000466945 & 0.000889304 & 0.000961414 & 0.00159726 \\
t-stat (a) & -0.678511 & -0.590607 & -0.50045 & -1.21477 & -2.42868 & -2.03531 & -0.966434 & 0.459871 & 0.846724 & 0.736624 \\
p-value (a) & 0.498068 & 0.555311 & 0.617193 & 0.225588 & 0.0158514 & 0.0428624 & 0.33475 & 0.646004 & 0.397949 & 0.462034 \\
Beta & 1.00344 & 0.948755 & 0.988722 & 0.95614 & 0.973826 & 0.964335 & 0.961529 & 0.969428 & 0.917101 & 0.939483 \\
SMB & -0.148308 & -0.0648357 & -0.0462055 & -0.0238776 & -0.0266012 & 0.0263161 & 0.0839441 & 0.171262 & 0.281605 & 0.41242 \\
HML & 0.239025 & 0.155692 & 0.101269 & 0.106429 & 0.0778953 & 0.0165455 & -0.0175955 & -0.0867703 & -0.156314 & -0.341642 \\
RMW & -0.111869 & -0.0110557 & 0.0185665 & 0.00576508 & 0.0209667 & -0.00892052 & -0.0491687 & -0.0659141 & -0.161005 & -0.131703 \\
CMA & -0.280953 & -0.193921 & -0.0665653 & -0.103535 & -0.0431201 & -0.0286169 & 0.0241227 & 0.0845927 & 0.0696832 & 0.121382 \\
R2 adjusted & 0.811513 & 0.907374 & 0.930042 & 0.968752 & 0.983616 & 0.985824 & 0.976129 & 0.923082 & 0.914936 & 0.817011
\end{tabular}

Figure 9. FF-5 factor performance without lag

Based on Fama-French 5 factor model,

12 month formation period and 12 month holding period,

\begin{tabular}{|c|c|c|c|c|c|c|c|c|c|c|}
\hline & Q1 & Q2 & Q3 & Q4 & Q5 & Q6 & Q7 & Q8 & Q9 & Q10 \\
\hline Avg returns & 0.0814872 & 0.085459 & 0.0925154 & 0.0791163 & 0.0817498 & 0.0819366 & 0.0804902 & 0.083878 & 0.077998 & 0.069759 \\
\hline vg excess returns & 0.0584308 & 1026 & 69459 & 5606 & 0586934 & 5588802 & 0574338 & .0608217 & 0.0549416 & .0467027 \\
\hline Volatility & 0.171633 & 152609 & 0.161428 & 0.153016 & 0.151229 & 0.155845 & 0.157379 & 0.169688 & 0.171551 & 0.188033 \\
\hline Sharpe ratio & 0.34044 & 0.408905 & 0.43028 & 0.366368 & 0.388109 & 0.377814 & 0.364939 & 0.358432 & 0.320265 & 0.248375 \\
\hline Alpha & 0.0029386 & 00544378 & 0.00613273 & -0.00352049 & -0.00588058 & -0.00319552 & -0.00259871 & -0.00480533 & -0.0120053 & -0.0185571 \\
\hline Std. error $(\alpha)$ & 0.00133456 & 000740132 & 0.000818406 & 0.000481685 & 0.000471171 & 0.000334989 & 0.000529286 & 0.000901414 & 0.00088152 & 0.00145408 \\
\hline t-stat (a) & 0.183494 & 0.612929 & 0.624459 & -0.609057 & -1.04006 & -0.794931 & -0.409153 & -0.44424 & -1.1349 & -1.0635 \\
\hline p-value $(\alpha)$ & 0.85457 & 0.540521 & 0.532937 & 0.543082 & 0.299393 & 0.427466 & 0.682805 & 0.657283 & 0.257583 & 0.288659 \\
\hline Beta & 0.927954 & 0.91728 & 0.958948 & 0.95196 & 0.969418 & 0.971892 & 0.960012 & 1.01006 & 1.00457 & 1.0475 \\
\hline SMB & 0.08377 & 0.0258851 & 0.0660197 & 0.0210325 & 0.0053022 & 0.0344573 & 0.036854 & 0.0636763 & 0.0811588 & 0.0521336 \\
\hline HML & 0.218011 & 0.169916 & 0.0553117 & 0.0809966 & 0.0896279 & 0.0101409 & -0.0171957 & -0.0663907 & -0.127853 & -0.164722 \\
\hline RMW & -0.187306 & -0.0579316 & -0.0955146 & -0.0182115 & 0.0561504 & -0.0303446 & -0.0638558 & -0.0476786 & -0.0499824 & -0.018304 \\
\hline CMA & -0.0350535 & -0.0476214 & 0.0259347 & -0.0498462 & 0.0202324 & -0.0359911 & -0.0502596 & -0.0486793 & -0.114906 & -0.223862 \\
\hline R2 adjusted & 0.847326 & 0.940789 & 0.93522 & 0.975162 & 0.975661 & 0.988432 & 0.971686 & 0.92926 & 0.93386 & 0.85032 \\
\hline
\end{tabular}

with a lag of 1 month,

the final results are (all numbers annualized):

Figure 10. FF-5 factor performance with a lag of 1-month 


\subsection{Sustainable Investing (Fama-Macbeth Analysis)}

The Fama-Macbeth analysis is conducted by following 4 steps, and the python code is available at the "Estimating factor premiums.ipynb" document on https://github.com/XUAN-FENG9/AFM_assignment.

The first step is adding new variables to the mutual funds' data (rolling regressions). In this step, I calculated the 3-year alpha, RMRF, SMB, HML, Sin-RF, and WML beta for each fund in each month. And I set a lookback period of 36-months.

The second step is creating a strategy based on mutual funds ("rank portfolios"). Following Huij \& Verbeek (2009), I create 10 quantile portfolios based on the funds' exposures to the factors (low to high from 1 to 10). Then I sort stocks based on their exposure to the Sin premium factor (Sin-RF). Figure 11 presents the cumulative returns of quantile portfolios. We can see that there are no significant return differences among different quantiles, except for quantile 10, which has the highest exposure to sin industry and the long term significant lowest return as expected. But for funds at quantile 1 and 2, which are expected to have lower returns because of lower exposure to sin industry, the result shows that, as expected, they do have slightly lower returns than other quantiles except quantile 10. But the difference is not very significant.

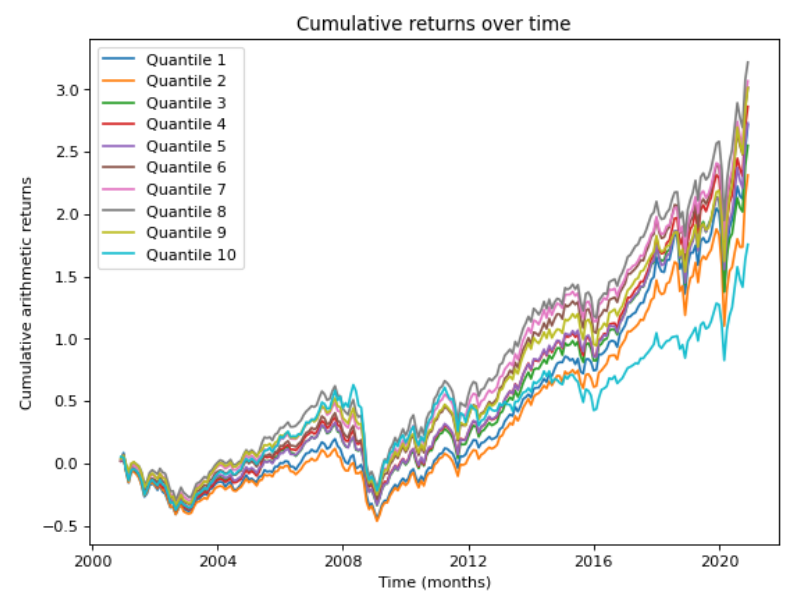

Figure 11. Plot of the cumulative returns of quantile portfolios

The third step is conducting a Cross-sectional Fama and MacBeth (1973) regression. In this step, I calculate the time-series Fama-French regressions on the 10 quantile portfolios to get betas. Then I run full-sample CAPM regressions on the quantile portfolios and plot annualized alphas, as shown in Figure 12:

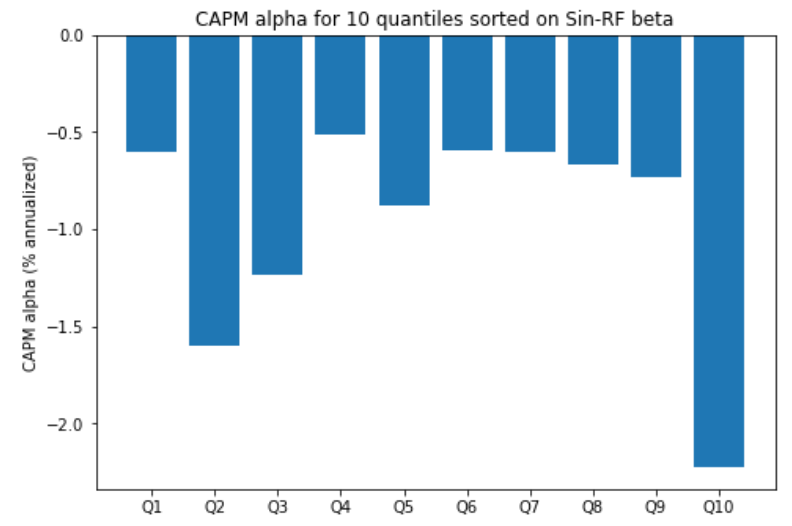

Figure 12. CAPM alpha for 10 quantiles sorted on Sin-RF factor beta

From Figure 12, we can see that alpha is not associated with sustainable investing. Funds that have higher exposure to the sin industry do not have higher alphas than funds with lower sin exposures, as suggested by Hong and Kacperczyk (2009). This result is aligned with the result presented in Figure 11.

The fourth step is calculating the Fama-MacBeth (1973) regressions on the quantiles. In this step, I calculate the cross-quantile regression on betas of the 10 quantiles to estimate the factor premium, and the result is presented 
in Table 1. It is worth noting that I have already lagged the betas by one month in the previous code. The significance of the premiums is presented in Table 2.

Table 1. Result of estimating Fama-MacBeth premiums (sorting on Sin-RF beta)

\begin{tabular}{ccc}
\hline Premium & Time-series average (monthly) & Hypothetical long-short (monthly) \\
\hline Mkt & $0.80 \%$ & $0.57 \%$ \\
SMB & $0.17 \%$ & $0.23 \%$ \\
HML & $0.35 \%$ & $0.25 \%$ \\
WML & $0.52 \%$ & $0.64 \%$ \\
Sin & $1.59 \%$ & $0.76 \%$ \\
\hline
\end{tabular}

Table 2. The significance of the premiums

\begin{tabular}{cc}
\hline Premium & Significance \\
\hline Gamma_Mkt & 2.706251 \\
Gamma_SMB & 0.471360 \\
Gamma_HML & 1.022293 \\
Gamma_WML & 0.955124 \\
Gamma_Sin-RF & 1.321257 \\
\hline
\end{tabular}

The result in Figure 13 shows that the estimated Sin premium is $1.59 \%$ per month - a positive value which means that funds that have higher exposures to the sin industry are expected to have higher returns, as concluded by Hong and Kacperczyk (2009). But the significance of this factor is not very significant (t-statistics 1.32), as shown in Figure 14. From this result, we can conclude that there is no significant return difference between funds that have high exposures to the Sin-RF factor and funds that have low exposures.

\section{Conclusion and Recommendation}

\subsection{Persistence Effect}

This research found the persistence effect of mutual funds, especially in the short term. The result is in line with the finding of Bollen and Busse (2005). From this research, I conclude that the shorter the holding period, the stronger the predictability. However, if the holding period is short, the lookback period cannot be very long because a long lookback period will bring historical factors that do not appear in the short-term forecasting period. The research result also shows that the Multi-factor model has the highest explaining power for the excess return regarding the underlying factors. Moreover, the result shows that the top decile of funds does not earn a statistically significant superior return. Some of the other decile funds earn, on the contrary, a higher superior return compared to the top decile.

Based on the results found in this research, I recommend to invest funds at quantile 7 to 10 that have higher returns than others. The investor can choose a benchmark not only based on the alpha but on the sharp ratio or information ratio. Investors are also recommended to use the Multi-factor model as a supplement to the CAPM model to explore the persistence effect.

This and previous researches do not reveal that how long the persistence will insist. Therefore, in future researches, it is interesting to investigate the length of the performance persistence. And it is also interesting to add other factors that can influence the fund performance, for example, the quality factors. Furthermore, I am also interested in exploring the impact of geographic differences on the persistence effect by conducting the above analysis on the US, EU, and emerging markets separately. The geographic difference is worth consideration because different markets have different trading limitations and different market efficiency, which can greatly influence the persistence effect. For example, it is reasonable to assume that emerging markets have less market efficiency than developed countries. Therefore, the persistence effect in emerging markets is more significant than that in developed countries.

\subsection{Sustainable Investing}

The result in this research shows that there is no significant alpha associated with sustainable investing. And there is no significant return differential between funds that have high/low exposure to the selected factor. By running the Fama-MacBeth regression, my result shows that there is a positive 'sin premium' - higher return for funds exposed more on the sin factor (comprise more stocks from companies in the sin industry). But this sin 
premium is not significant, with a t statistic that equals 1.32 . Therefore, from my study, funds that investing in the sin industry and that investing in the sustainable industry has no significant difference in abnormal returns.

In this research, I use the arithmetic average excess return of stocks in the tobacco, alcohol, and oil \& gas industry as a factor proxy for the premium of exposure on sin industries. However, in future studies, this factor premium can be built more complex by using the weighted average and including stocks in other sin industries, although hard to find the data, such as unethical entertainment, weapon manufacturing., etc. Moreover, it is also interesting to investigating whether the sin premium varies geographically. For example, whether the effect of sin exposure is different between developed and developing countries.

Furthermore, the result in this research cannot totally deny the benefit of sustainable investing that prioritizes the delivery of social and environmental impacts. Sustainable investing needs a different assessment system that not only includes financial performance measured based on risk-adjusted returns. In future research, it is attractive to evaluate the non-financial outcomes of sustainable investing individually, with a tailored, predetermined matrix. More efforts are also needed to construct a suitable proxy that can reflect these non-financial outcomes thoroughly.

\section{References}

Berk, J. B. (2005). Five myths of active portfolio management. The Journal of Portfolio Management, 31(3), 27-31. https://doi.org/10.3905/jpm.2005.500350

Bollen, N. P., \& Busse, J. A. (2005). Short-term persistence in mutual fund performance. The Review of Financial Studies, 18(2), 569-597. https://doi.org/10.1093/rfs/hhi007

Bolton, P., \& Kacperczyk, M. (2020). Carbon Premium Around the World. CEPR Discussion Paper No. DP14567.

Carhart, M. M. (1997). On persistence in mutual fund performance. The Journal of Finance, 52(1), 57-82. https://doi.org/10.1111/j.1540-6261.1997.tb03808.x

Cremers, M., \& Pareek, A. (2016). Patient capital outperformance: The investment skill of high active share managers who trade infrequently. Journal of Financial Economics, 122, 288-306. https://doi.org/10.1016/j.jfineco.2016.08.003

Elton, E. J., Gruber, M. J., \& Blake, C. R. (1996). The persistence of risk-adjusted mutual fund performance. Journal of Business, 133-157. https://www.jstor.org/stable/2353461

Friede, G., Busch, T., \& Bassen, A. (2015). ESG and financial performance aggregated evidence from more than 2000 empirical studies, Journal of Sustainable Finance \& Investment, 5, 210-233. https://doi.org/10.1080/20430795.2015.1118917

Gibson, R., \& Krüger, P. (2017). The Sustainability Footprint of Institutional Investors, working paper. Swiss Finance Institute Research Paper Series, 17-05.

Gibson, R., Krueger, P., \& Schmidt, P. S. (2019). ESG rating disagreement and stock returns. Swiss Finance Institute Research Paper, 19-67.

Hendricks, D., Patel, J., \& Zeckhauser, R. (1993). Hot hands in mutual funds: Short-run persistence of relative performance, 1974-1988. The Journal of Finance, 48(1), 93-130. https://doi.org/10.1111/j.1540-6261.1993.tb04703.x

Hong, H., \& Kacperczyk, M. (2009). The price of sin: The effects of social norms on markets. Journal of Financial Economics, 93, 15-36. https://doi.org/10.1016/j.jfineco.2008.09.001

Hong, H., Li, F., \& Xu, J. (2018). Climate risks and market efficiency. Journal of Econometrics, 208, 265-281. https://doi.org/10.1016/j.jeconom.2018.09.015

Huij, J. (2007). New Insights into Mutual Funds: Performance and Family Strategies. ERIM Series Research in Management, (99).

Huij, J., \& Verbeek, M. (2007). Cross-sectional learning and short-run persistence in mutual fund performance. Journal of Banking \& Finance, 31(3), 973-997. https://doi.org/10.1016/j.jbankfin.2006.08.002

Pastor, L., Stambaugh, R., \& Taylor, L. (2020). Sustainable Investing in Equilibrium. Journal of Financial Economics, In Press. https://doi.org/10.1016/j.jfineco.2020.12.011

Schoenmaker, D., \& Schramade, W. (2019). Investing for Long-Term Value Creation. Journal of Sustainable Finance \& Investment, 9, 356-377. https://doi.org/10.1080/20430795.2019.1625012 
Van Nieuwerburgh, S., \& Veldkamp, L. (2010). Information acquisition and portfolio under-diversification, Review of Economic Studies, 77, 779-805. https://doi.org/10.1111/j.1467-937X.2009.00583.x

\section{Appendix 1. Results for core analysis}

1. CAPM Model (36-months lookback period - 12-months holding period)
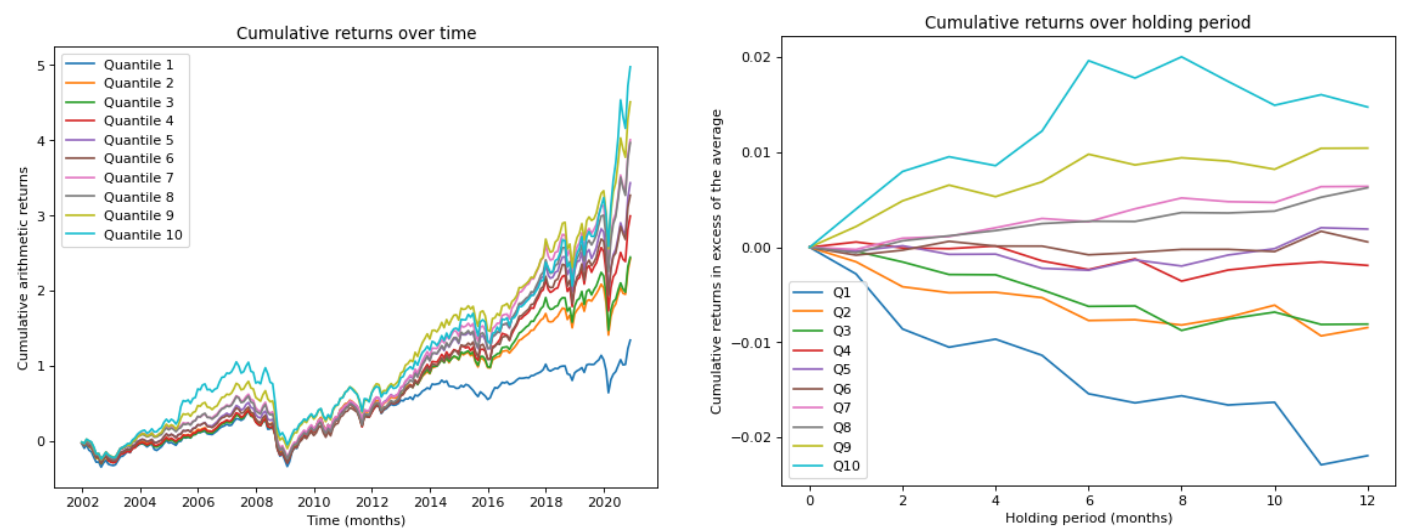

\begin{tabular}{|c|c|c|c|c|c|c|c|c|c|c|}
\hline & Q1 & Q2 & Q3 & Q4 & Q5 & Q6 & Q7 & Q8 & Q9 & Q10 \\
\hline Avg returns & 0.0566497 & 0.0756524 & 0.0761634 & 0.0848271 & 0.090166 & 0.0882847 & 0.0964259 & 0.0962094 & 0.101924 & 0.107889 \\
\hline Avg excess returns & 0.0335934 & 0.0525961 & 0.053107 & 0.0617707 & 0.0671096 & 0.0652283 & 0.0733696 & 0.073153 & 0.0788677 & 0.0848322 \\
\hline Volatility & 0.152518 & 0.145205 & 0.14648 & 0.152235 & 0.151005 & 0.15161 & 0.149642 & 0.150927 & 0.152551 & 0.162834 \\
\hline Sharpe ratio & 0.220259 & 0.362219 & 0.362555 & 0.405759 & 0.444419 & 0.430238 & 0.4903 & 0.484691 & 0.516993 & 0.520975 \\
\hline Alpha & -0.0381602 & -0.0186845 & -0.019981 & -0.0146319 & -0.00928514 & -0.011566 & -0.00225469 & -0.00296475 & 0.00297001 & 0.00714766 \\
\hline Std. error ( $\alpha)$ & 0.00107243 & 0.000650054 & 0.000479022 & 0.000496842 & 0.000325499 & 0.000316797 & 0.000322444 & 0.000392586 & 0.000612511 & 0.00111363 \\
\hline t-stat (a) & -2.96524 & -2.39526 & -3.47601 & -2.45415 & -2.37716 & -3.04243 & -0.582708 & -0.629321 & 0.404075 & 0.534864 \\
\hline$p$-value $(a)$ & 0.00334886 & 0.0174241 & 0.000610132 & 0.0148776 & 0.0182803 & 0.00262424 & 0.560671 & 0.529775 & 0.686539 & 0.59327 \\
\hline Beta & 0.931909 & 0.92657 & 0.946972 & 0.984387 & 0.984298 & 0.988809 & 0.975601 & 0.981172 & 0.978687 & 0.998857 \\
\hline
\end{tabular}

2. CAPM Model (60-months lookback period - 12-months holding period)
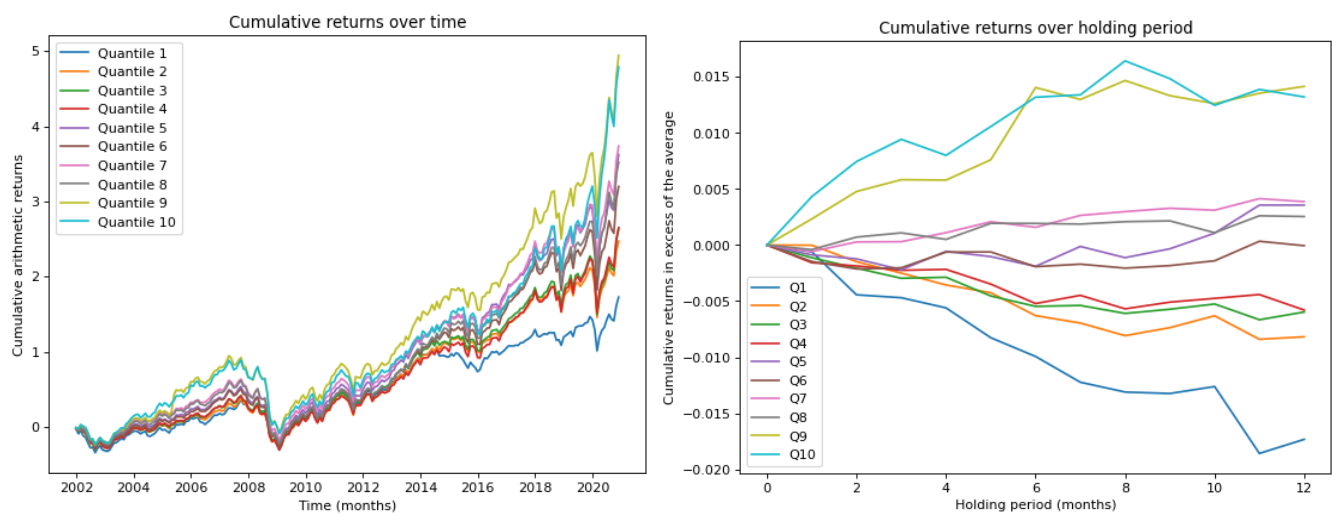

\begin{tabular}{rrrrrrrrrrr} 
& Q1 & Q2 & Q3 & Q4 & Q5 & Q6 & Q7 & Q8 & Q9 & Q10 \\
\hline Avg returns & 0.0632332 & 0.0761355 & 0.0792584 & 0.0795353 & 0.0926525 & 0.0875984 & 0.0930183 & 0.0911531 & 0.107178 & 0.105879 \\
Avg excess returns & 0.0401768 & 0.0530791 & 0.056202 & 0.0564789 & 0.0695962 & 0.064542 & 0.0699619 & 0.0680967 & 0.0841215 & 0.0828223 \\
Volatility & 0.14305 & 0.143905 & 0.148934 & 0.148736 & 0.152996 & 0.153226 & 0.146985 & 0.150512 & 0.160853 & 0.160793 \\
Sharpe ratio & 0.280859 & 0.368848 & 0.377361 & 0.379725 & 0.454888 & 0.42122 & 0.475979 & 0.452434 & 0.52297 & 0.515087 \\
Alpha & -0.0272316 & -0.0184289 & -0.0184374 & -0.0184377 & -0.00787584 & -0.0131697 & -0.00404865 & -0.00776455 & 0.00605559 & 0.00386169 \\
Std. error (a) & 0.000938644 & 0.000496432 & 0.000457488 & 0.000367838 & 0.000351808 & 0.00031674 & 0.000336487 & 0.000389977 & 0.0000963442 & 0.00086115 \\
t-stat (a) & -2.41764 & -3.09356 & -3.35845 & -4.17705 & -1.86556 & -3.4649 & -1.00268 & -1.65919 & 0.523781 & 0.373695 \\
p-value (a) & 0.0164142 & 0.00222693 & 0.000919763 & $4.21929 \mathrm{e}-05$ & 0.0633981 & 0.000634545 & 0.317089 & 0.0984642 & 0.600944 & 0.708982 \\
Beta & 0.882861 & 0.929137 & 0.964484 & 0.967613 & 0.996459 & 0.999164 & 0.957386 & 0.978277 & 1.00316 & 1.01326 \\
SMB & $\mathrm{NaN}$ & $\mathrm{NaN}$ & $\mathrm{NaN}$ & $\mathrm{NaN}$ & $\mathrm{NaN}$ & $\mathrm{NaN}$ & $\mathrm{NaN}$ & $\mathrm{NaN}$ & $\mathrm{NaN}$ & $\mathrm{NaN}$ \\
HML & $\mathrm{NaN}$ & $\mathrm{NaN}$ & $\mathrm{NaN}$ & $\mathrm{NaN}$ & $\mathrm{NaN}$ & $\mathrm{NaN}$ & $\mathrm{NaN}$ & $\mathrm{NaN}$ & $\mathrm{NaN}$ & $\mathrm{NaN}$
\end{tabular}


3. FF 3 factor model (36-months lookback period - 12-months holding period)
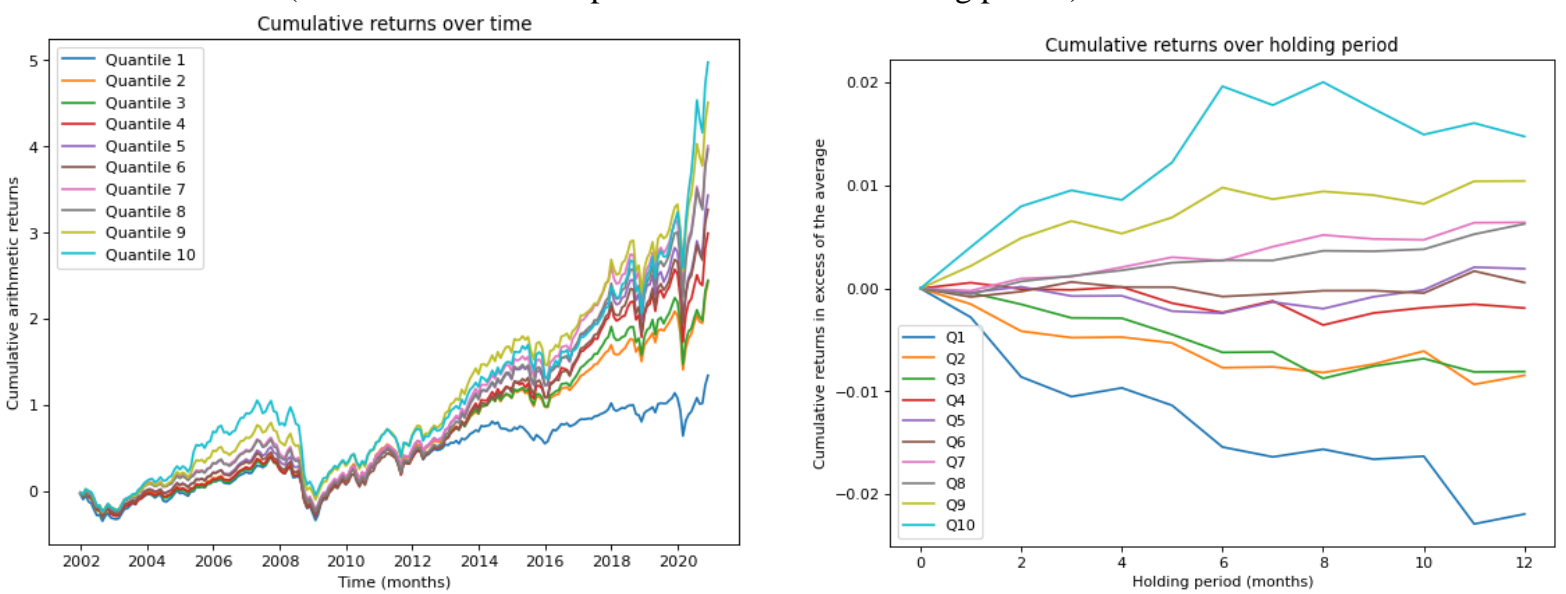

\begin{tabular}{rrrrrrrrrrr} 
& Q1 & Q2 & Q3 & Q4 & Q5 & Q6 & Q7 & Q8 & Q9 & Q10 \\
\hline Avg returns & 0.0566497 & 0.0756524 & 0.0761634 & 0.0848271 & 0.090166 & 0.0882847 & 0.0964259 & 0.0962094 & 0.101924 & 0.107889 \\
Avg excess returns & 0.0335934 & 0.0525961 & 0.053107 & 0.0617707 & 0.0671096 & 0.0652283 & 0.0733696 & 0.073153 & 0.0788677 & 0.0848322 \\
Volatility & 0.152518 & 0.145205 & 0.14648 & 0.152235 & 0.151005 & 0.15161 & 0.149642 & 0.150927 & 0.152551 & 0.162834 \\
Sharpe ratio & 0.220259 & 0.362219 & 0.362555 & 0.405759 & 0.444419 & 0.430238 & 0.4903 & 0.484691 & 0.516993 & 0.520975 \\
Alpha & -0.034878 & -0.0175281 & -0.0185175 & -0.0136673 & -0.00825067 & -0.0125492 & -0.0024049 & -0.00444989 & -0.00118578 & -0.00146578 \\
Std. error (a) & 0.00105049 & 0.000638363 & 0.000471678 & 0.00049272 & 0.000313667 & 0.000307741 & 0.000324646 & 0.000383082 & 0.000561557 & 0.00101539 \\
t-stat (a) & -2.7668 & -2.28816 & -3.27157 & -2.31154 & -2.192 & -3.3982 & -0.617314 & -0.968003 & -0.175967 & -0.120297 \\
p-value (a) & 0.00613389 & 0.0230611 & 0.00123845 & 0.0217116 & 0.0294098 & 0.000802724 & 0.537655 & 0.334087 & 0.860479 & 0.904356 \\
Beta & 0.898651 & 0.904913 & 0.934036 & 0.971513 & 0.97117 & 0.980019 & 0.972145 & 0.973552 & 0.963706 & 0.983676 \\
SMB & 0.0695493 & 0.0100866 & 0.158589 & 0.0790936 & 0.00629442 & $4.66961 \mathrm{e}-05$ & 0.214673 & 0.000419689 & $3.37329 \mathrm{e}-08$ & $1.08278 \mathrm{e}-06$ \\
HML & 0.00848942 & 0.0945524 & 0.00991152 & 0.0868015 & 0.00438379 & 0.0310627 & 0.798178 & 0.00616018 & $1.8733 \mathrm{e}-07$ & $1.5031 \mathrm{e}-09$
\end{tabular}

4. FF 3 factor model (60-months lookback period - 12-months holding period)
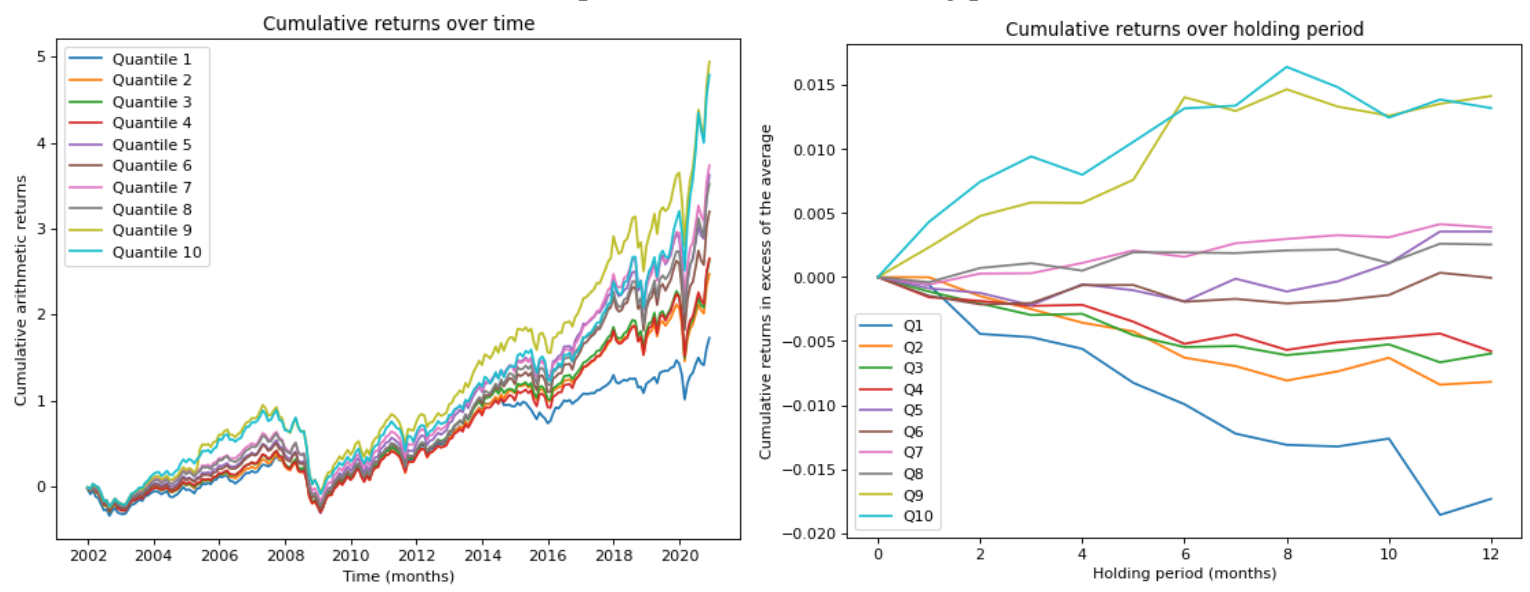

\begin{tabular}{rrrrrrrrrrr} 
& Q1 & Q2 & Q3 & Q4 & Q5 & Q6 & Q7 & Q8 & Q9 & Q10 \\
\hline Avg returns & 0.0632332 & 0.0761355 & 0.0792584 & 0.0795353 & 0.0926525 & 0.0875984 & 0.0930183 & 0.0911531 & 0.107178 & 0.105879 \\
Avg excess returns & 0.0401768 & 0.0530791 & 0.056202 & 0.0564789 & 0.0695962 & 0.064542 & 0.0699619 & 0.0680967 & 0.0841215 & 0.0828223 \\
Volatility & 0.14305 & 0.143905 & 0.148934 & 0.148736 & 0.152996 & 0.153226 & 0.146985 & 0.150512 & 0.160853 & 0.160793 \\
Sharpe ratio & 0.280859 & 0.368848 & 0.377361 & 0.379725 & 0.454888 & 0.42122 & 0.475979 & 0.452434 & 0.52297 & 0.515087 \\
Alpha & -0.0267479 & -0.018617 & -0.0173644 & -0.0178108 & -0.0061271 & -0.0125582 & -0.00441864 & -0.00976206 & 0.00306042 & -0.00342682 \\
Std. error (a) & 0.000944687 & 0.000497195 & 0.000449193 & 0.000368071 & 0.000338718 & 0.000308349 & 0.000328322 & 0.00037263 & 0.000931691 & 0.000736 \\
t-stat (a) & -2.35951 & -3.12033 & -3.22141 & -4.03246 & -1.50743 & -3.39393 & -1.12152 & -2.18315 & 0.273734 & -0.388001 \\
p-value (a) & 0.0191587 & 0.00204395 & 0.00146532 & $7.56968 \mathrm{e}-05$ & 0.133111 & 0.000814696 & 0.263267 & 0.0300639 & 0.784541 & 0.698384 \\
Beta & 0.87102 & 0.920182 & 0.949798 & 0.961141 & 0.985818 & 0.987107 & 0.945742 & 0.970335 & 0.97402 & 0.985029 \\
SMB & 0.306805 & 0.0540711 & 0.0265599 & 0.305885 & 0.343457 & 0.00269569 & $9.59753 \mathrm{e}-05$ & $2.1557 \mathrm{e}-05$ & $1.47672 \mathrm{e}-05$ & $1.11321 \mathrm{e}-13$ \\
HML & 0.616946 & 0.899812 & 0.0363106 & 0.148296 & $3.84076 \mathrm{e}-05$ & 0.0648406 & 0.59095 & 0.000137835 & 0.0317707 & $1.04647 \mathrm{e}-11$
\end{tabular}


5. Carhart model (36-months lookback period - 12-months holding period)
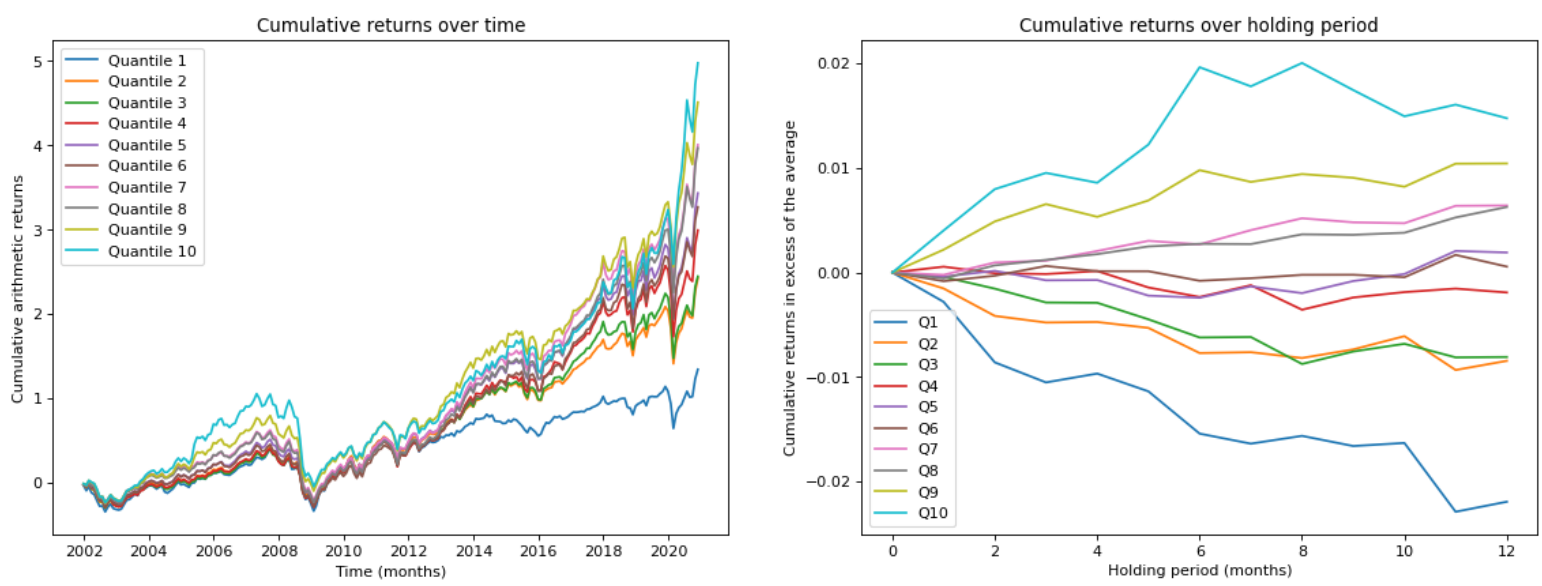

\begin{tabular}{rrrrrrrrrrr} 
& Q1 & Q2 & Q3 & Q4 & Q5 & Q6 & Q7 & Q8 & Q9 & Q10 \\
\hline Avg returns & 0.0566497 & 0.0756524 & 0.0761634 & 0.0848271 & 0.090166 & 0.0882847 & 0.0964259 & 0.0962094 & 0.101924 & 0.107889 \\
Avg excess returns & 0.0335934 & 0.0525961 & 0.053107 & 0.0617707 & 0.0671096 & 0.0652283 & 0.0733696 & 0.073153 & 0.0788677 & 0.0848322 \\
Volatility & 0.152518 & 0.145205 & 0.14648 & 0.152235 & 0.151005 & 0.15161 & 0.149642 & 0.150927 & 0.152551 & 0.162834 \\
Sharpe ratio & 0.220259 & 0.362219 & 0.362555 & 0.405759 & 0.444419 & 0.430238 & 0.4903 & 0.484691 & 0.516993 & 0.520975 \\
Alpha & -0.030151 & -0.0157173 & -0.0167583 & -0.0122 & -0.00720156 & -0.0118695 & -0.00254191 & -0.00479772 & -0.00294935 & -0.00466853 \\
Std. error (a) & 0.00100972 & 0.000630925 & 0.000460071 & 0.000486089 & 0.000307842 & 0.000306288 & 0.000326422 & 0.000384643 & 0.00055277 & 0.00099931 \\
t-stat (a) & -2.48839 & -2.07596 & -3.03546 & -2.09152 & -1.94947 & -3.22939 & -0.648932 & -1.03943 & -0.444631 & -0.389313 \\
p-value (a) & 0.0135641 & 0.0390439 & 0.00268712 & 0.0376137 & 0.0524925 & 0.00142767 & 0.51705 & 0.299729 & 0.657017 & 0.697416 \\
Beta & 0.852716 & 0.887317 & 0.916941 & 0.957254 & 0.960975 & 0.973414 & 0.973476 & 0.976932 & 0.980843 & 1.0148 \\
SMB & 0.0430799 & 0.00715939 & 0.119683 & 0.0616247 & 0.0039218 & $3.16684 \mathrm{e}-05$ & 0.220082 & 0.000465508 & $3.05725 \mathrm{e}-08$ & $1.05046 \mathrm{e}-06$ \\
HML & 0.15339 & 0.378106 & 0.118616 & 0.375981 & 0.0543959 & 0.00758868 & 0.89263 & 0.0161836 & $1.41871 \mathrm{e}-05$ & $2.21069 \mathrm{e}-07$ \\
WML & $6.93002 \mathrm{e}-06$ & 0.00518555 & 0.000216093 & 0.00330961 & 0.000941462 & 0.0300931 & 0.680094 & 0.374676 & 0.00192885 & 0.00184061
\end{tabular}

6. Carhart model (60-months lookback period - 12-months holding period)
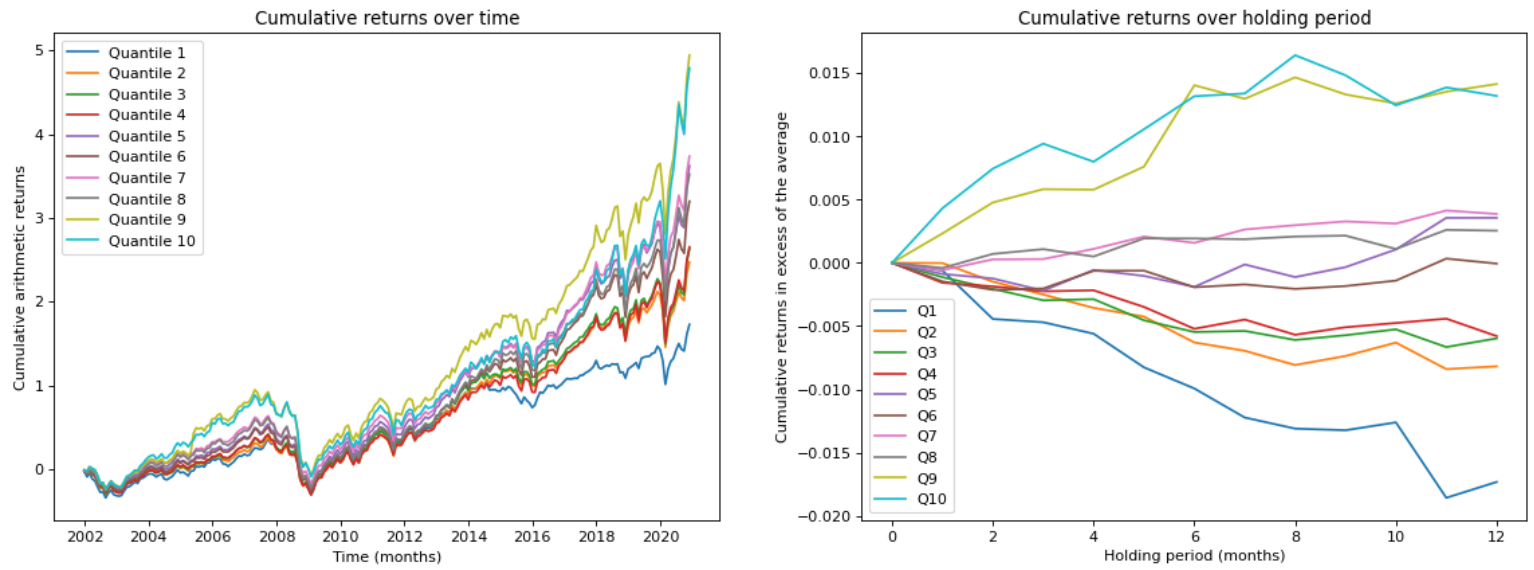

\begin{tabular}{rrrrrrrrrrr} 
& Q1 & Q2 & Q3 & Q4 & Q5 & Q6 & Q7 & Q8 & Q9 & Q10 \\
\hline Avg returns & 0.0632332 & 0.0761355 & 0.0792584 & 0.0795353 & 0.0926525 & 0.0875984 & 0.0930183 & 0.0911531 & 0.107178 & 0.105879 \\
Avg excess returns & 0.0401768 & 0.0530791 & 0.056202 & 0.0564789 & 0.0695962 & 0.064542 & 0.0699619 & 0.0680967 & 0.0841215 & 0.0828223 \\
Volatility & 0.14305 & 0.143905 & 0.148934 & 0.148736 & 0.152996 & 0.153226 & 0.146985 & 0.150512 & 0.160853 & 0.160793 \\
Sharpe ratio & 0.280859 & 0.368848 & 0.377361 & 0.379725 & 0.454888 & 0.42122 & 0.475979 & 0.452434 & 0.52297 & 0.515087 \\
Alpha & -0.0238252 & -0.0171175 & -0.0157433 & -0.0160388 & -0.0048786 & -0.0115431 & -0.00395393 & -0.010746 & 0.00174143 & -0.00601554 \\
Std. error (a) & 0.000930511 & 0.000490255 & 0.000439024 & 0.000351344 & 0.000330627 & 0.000302861 & 0.000328822 & 0.000369166 & 0.000933111 & 0.000720403 \\
t-stat (a) & -2.1337 & -2.90962 & -2.98832 & -3.80414 & -1.22963 & -3.17612 & -1.00204 & -2.42573 & 0.155522 & -0.695853 \\
p-value (a) & 0.0339593 & 0.00398514 & 0.0031193 & 0.000183779 & 0.22013 & 0.00170364 & 0.317409 & 0.0160728 & 0.876551 & 0.487245 \\
Beta & 0.842618 & 0.905611 & 0.934045 & 0.943922 & 0.973686 & 0.977243 & 0.941226 & 0.979896 & 0.986838 & 1.01018 \\
SMB & 0.259145 & 0.0409555 & 0.017436 & 0.223768 & 0.280598 & 0.00161044 & $8.0091 \mathrm{e}-05$ & $2.3481 \mathrm{e}-05$ & $1.69659 \mathrm{e}-05$ & $6.15101 \mathrm{e}-14$ \\
HML & 0.734871 & 0.352126 & 0.269675 & 0.892547 & 0.00178746 & 0.348342 & 0.372696 & 0.00232871 & 0.0883265 & $3.8242 \mathrm{e}-09$ \\
WML & 0.00225832 & 0.00292516 & 0.000348805 & $1.38994 \mathrm{e}-06$ & 0.000257397 & 0.00113756 & 0.165863 & 0.00935316 & 0.165778 & 0.00049626
\end{tabular}


Models 7-11 are devoted to explore the short-term and long-term effect

7. FF 3 factor model (12-months formation period - 12-months holding period)
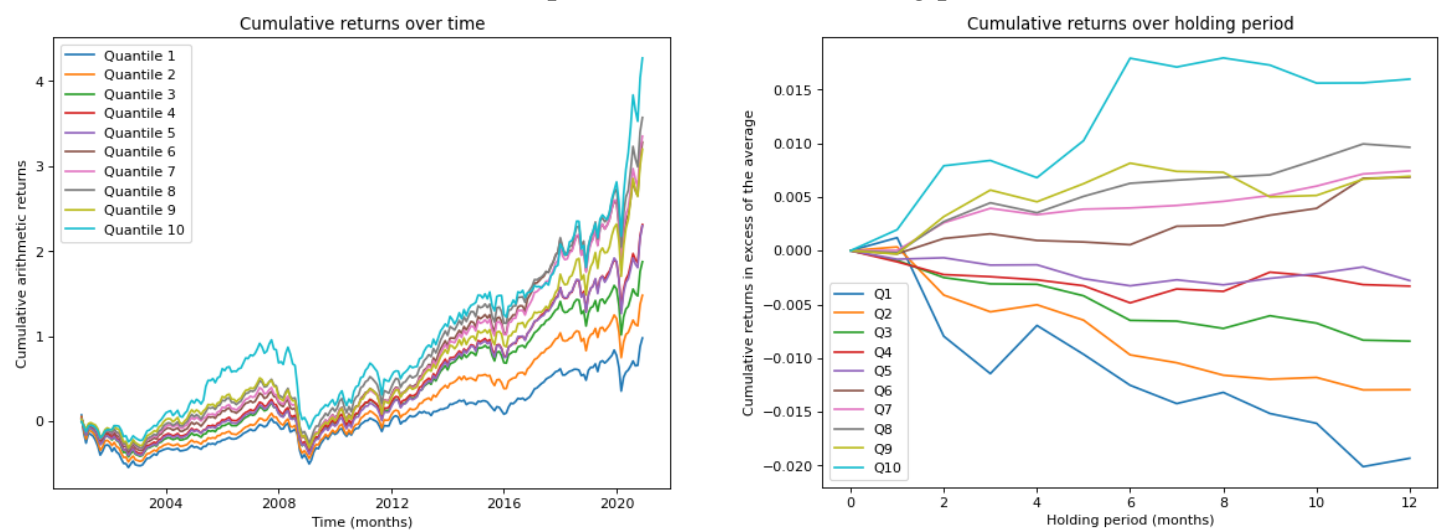

\begin{tabular}{rrrrrrrrrrr} 
& Q1 & Q2 & Q3 & Q4 & Q5 & Q6 & Q7 & Q8 & Q9 & Q10 \\
\hline Avg returns & 0.0500125 & 0.0584729 & 0.0644541 & 0.0713007 & 0.072007 & 0.0848017 & 0.0855303 & 0.0884343 & 0.0848952 & 0.0967081 \\
Avg excess returns & 0.0269561 & 0.0354166 & 0.0413977 & 0.0482443 & 0.0489506 & 0.0617453 & 0.062474 & 0.0653779 & 0.0618388 & 0.0736517 \\
Volatility & 0.175533 & 0.159218 & 0.150625 & 0.149138 & 0.155007 & 0.153329 & 0.152653 & 0.155543 & 0.159943 & 0.162119 \\
Sharpe ratio & 0.153567 & 0.222441 & 0.27484 & 0.323488 & 0.315796 & 0.402699 & 0.409254 & 0.42032 & 0.386631 & 0.454308 \\
Alpha & -0.0460242 & -0.0339903 & -0.0234375 & -0.0156978 & -0.0183553 & -0.00436027 & -0.00392067 & -0.00300466 & -0.00922541 & 0.00288222 \\
Std. error (a) & 0.00135976 & 0.000773537 & 0.000494088 & 0.000391225 & 0.000364134 & 0.000302676 & 0.000334434 & 0.000426884 & 0.000567743 & 0.00110663 \\
t-stat (a) & -2.8206 & -3.66178 & -3.95299 & -3.34373 & -4.20068 & -1.20048 & -0.976942 & -0.586549 & -1.3541 & 0.217041 \\
p-value (a) & 0.0052012 & 0.00030916 & 0.000102031 & 0.000961257 & $3.77491 \mathrm{e}-05$ & 0.231157 & 0.329598 & 0.558067 & 0.176998 & 0.828364 \\
Beta & 1.00781 & 0.978016 & 0.944862 & 0.945682 & 0.985453 & 0.971184 & 0.968312 & 0.975554 & 0.984456 & 0.931638 \\
SMB & 0.046833 & 0.0353721 & 0.0739323 & 0.5194 & 0.374651 & 0.0372586 & 0.0488625 & 0.000281924 & $6.51665 \mathrm{e}-07$ & $1.99804 \mathrm{e}-05$ \\
HML & 0.107405 & 0.000480193 & 0.602561 & 0.915304 & 0.150266 & 0.00867231 & 0.236319 & 0.0492819 & 0.0264871 & 0.00018053
\end{tabular}

8. FF 3 factor model (12-months formation period - 3-months holding period)
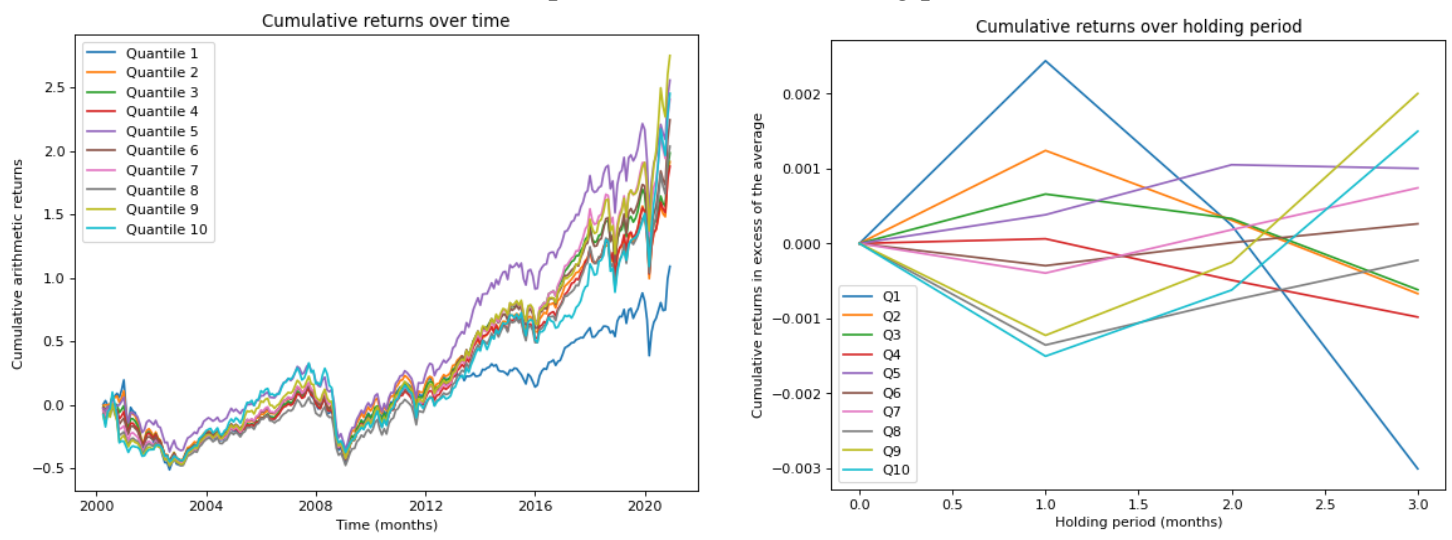

\begin{tabular}{rrrrrrrrrrrr} 
& Q1 & Q2 & Q3 & Q4 & Q5 & Q6 & Q7 & Q8 & Q9 & Q10 \\
\hline Avg returns & 0.051763 & 0.0641979 & 0.0644608 & 0.0624844 & 0.0731073 & 0.069132 & 0.0716928 & 0.0665073 & 0.0784013 & 0.0757074 \\
Avg excess returns & 0.0287066 & 0.0411415 & 0.0414044 & 0.0394281 & 0.0500509 & 0.0460756 & 0.0486364 & 0.043451 & 0.0553449 & 0.0526511 \\
Volatility & 0.178215 & 0.157101 & 0.151701 & 0.150207 & 0.152378 & 0.155742 & 0.156813 & 0.159375 & 0.169146 & 0.175749 \\
Sharpe ratio & 0.161078 & 0.261879 & 0.272933 & 0.262492 & 0.328466 & 0.295846 & 0.310155 & 0.272634 & 0.327201 & 0.299582 \\
Alpha & -0.0279731 & -0.0131668 & -0.0123133 & -0.0138907 & -0.00382723 & -0.0108371 & -0.00833629 & -0.0146337 & -0.00582695 & -0.00595088 \\
Std. error (a) & 0.00156316 & 0.000871215 & 0.000576398 & 0.000454724 & 0.000597385 & 0.000307278 & 0.000392683 & 0.000476453 & 0.000816583 & 0.00133127 \\
t-stat (a) & -1.49127 & -1.25943 & -1.78021 & -2.54562 & -0.533886 & -2.93901 & -1.76909 & -2.55949 & -0.594648 & -0.372507 \\
p-value (a) & 0.137177 & 0.209075 & 0.0762809 & 0.0115221 & 0.593904 & 0.00360702 & 0.0781236 & 0.011084 & 0.552627 & 0.709838 \\
Beta & 1.00325 & 0.950865 & 0.944531 & 0.944406 & 0.949178 & 0.974857 & 0.974294 & 0.973024 & 0.990497 & 0.943133 \\
SMB & 0.431561 & 0.842479 & 0.438458 & 0.18016 & 0.172836 & 0.00804829 & 0.00134392 & $6.92317 \mathrm{e}-08$ & $6.08385 \mathrm{e}-08$ & $4.76087 \mathrm{e}-06$ \\
HML & 0.17294 & 0.127945 & 0.00187216 & 0.00609008 & $6.71935 \mathrm{e}-06$ & 0.0147316 & 0.113217 & $9.83115 \mathrm{e}-06$ & $3.93621 \mathrm{e}-05$ & $6.27194 \mathrm{e}-09$
\end{tabular}


9. FF 3 factor model (12-months formation period - 1-months holding period)
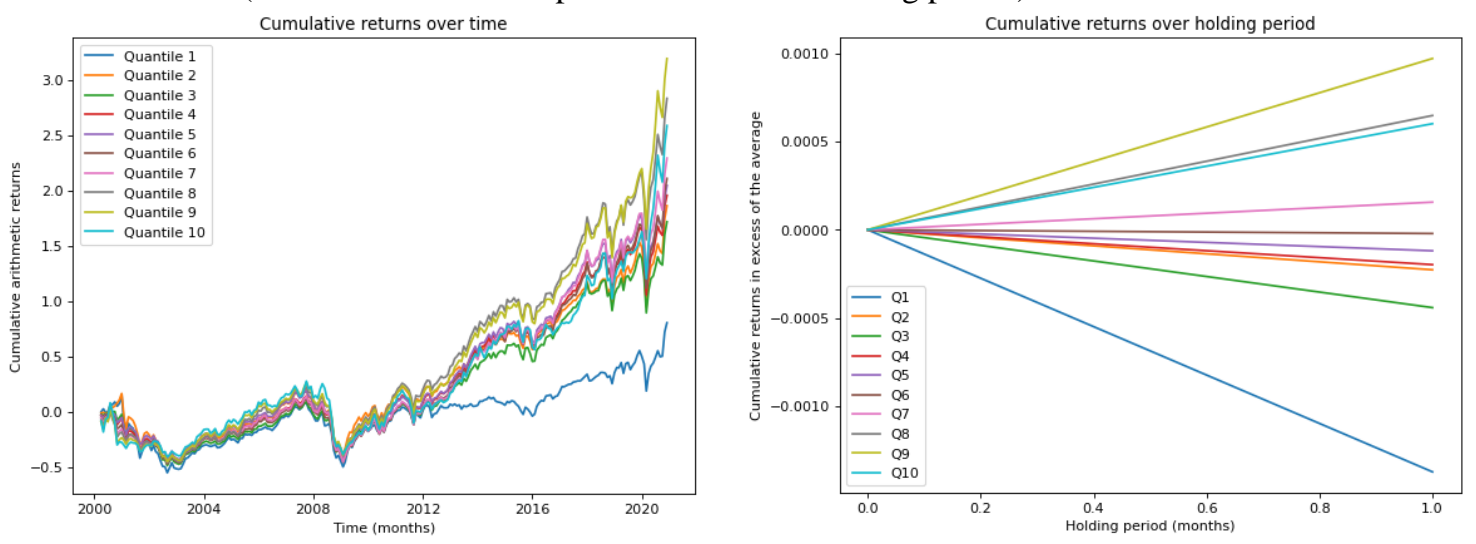

\begin{tabular}{rrrrrrrrrrr} 
& Q1 & Q2 & Q3 & Q4 & Q5 & Q6 & Q7 & Q8 & Q9 & Q10 \\
\hline Avg returns & 0.0452338 & 0.0637976 & 0.0603213 & 0.0642705 & 0.0655436 & 0.06713 & 0.070013 & 0.0779715 & 0.0832083 & 0.0772206 \\
Avg excess returns & 0.0221774 & 0.0407412 & 0.0372649 & 0.0412141 & 0.0424872 & 0.0440736 & 0.0469566 & 0.0549152 & 0.0601519 & 0.0541642 \\
Volatility & 0.180294 & 0.159401 & 0.153574 & 0.152766 & 0.151575 & 0.155646 & 0.156224 & 0.160203 & 0.165535 & 0.173775 \\
Sharpe ratio & 0.123007 & 0.255589 & 0.242651 & 0.269785 & 0.280304 & 0.283165 & 0.300572 & 0.342785 & 0.363378 & 0.311691 \\
Alpha & -0.0347736 & -0.0131475 & -0.0169316 & -0.0132447 & -0.0117541 & -0.012335 & -0.00961551 & -0.00372933 & 0.000356537 & -0.00429788 \\
Std. error (a) & 0.00158872 & 0.00104044 & 0.000605407 & 0.000490091 & 0.000385096 & 0.000318927 & 0.000381821 & 0.000601779 & 0.00081285 & 0.00131899 \\
t-stat (a) & -1.82398 & -1.05304 & -2.33061 & -2.25207 & -2.54355 & -3.22306 & -2.09861 & -0.516432 & 0.0365521 & -0.271538 \\
p-value (a) & 0.0693727 & 0.293362 & 0.0205866 & 0.0252037 & 0.0115888 & 0.00144049 & 0.0368757 & 0.606018 & 0.970872 & 0.786206 \\
Beta & 1.01393 & 0.949756 & 0.955307 & 0.956483 & 0.956938 & 0.977764 & 0.97488 & 0.962852 & 0.964452 & 0.933809 \\
SMB & 0.454004 & 0.518517 & 0.418349 & 0.527125 & 0.0930471 & 0.21837 & 0.0262676 & $3.57587 \mathrm{e}-08$ & $1.08287 \mathrm{e}-08$ & $2.96431 \mathrm{e}-06$ \\
HML & 0.645285 & 0.0408386 & 0.0313683 & 0.0153401 & $1.33334 \mathrm{e}-05$ & 0.390966 & 0.323345 & 0.0225239 & $4.37576 \mathrm{e}-05$ & $3.23281 \mathrm{e}-07$
\end{tabular}

10. FF 3 factor model (3-months formation period - 12-months holding period)
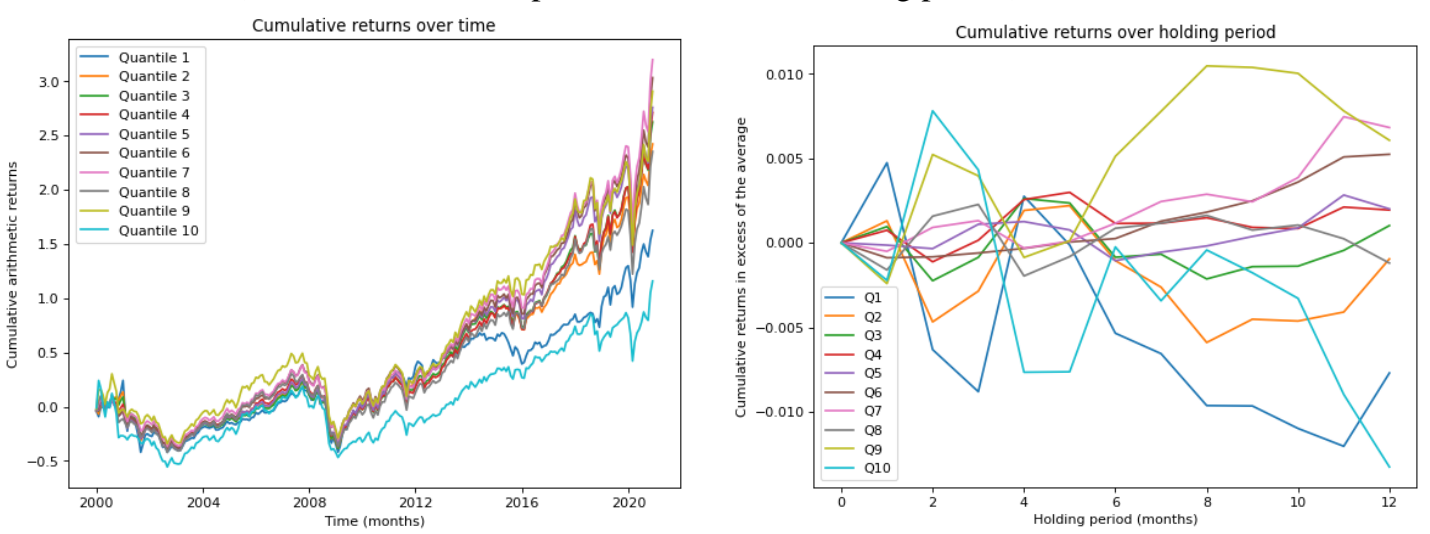

\begin{tabular}{rrrrrrrrrrr} 
& Q1 & Q2 & Q3 & Q4 & Q5 & Q6 & Q7 & Q8 & Q9 & Q10 \\
\hline Avg returns & 0.0628828 & 0.0711604 & 0.073585 & 0.0747077 & 0.0747319 & 0.0788034 & 0.0807985 & 0.0705507 & 0.0797185 & 0.0550556 \\
Avg excess returns & 0.0398264 & 0.048104 & 0.0505286 & 0.0516514 & 0.0516755 & 0.055747 & 0.0577422 & 0.0474943 & 0.0566621 & 0.0319992 \\
Volatility & 0.180451 & 0.156313 & 0.154545 & 0.15427 & 0.151113 & 0.155499 & 0.156106 & 0.159284 & 0.170317 & 0.190587 \\
Sharpe ratio & 0.220704 & 0.307742 & 0.32695 & 0.334812 & 0.341965 & 0.358503 & 0.369892 & 0.298174 & 0.332686 & 0.167898 \\
Alpha & -0.0147389 & -0.00428616 & -0.00349268 & -0.00388388 & -0.00347667 & -0.0014287 & -0.000449277 & -0.0120559 & -0.0076739 & -0.0352023 \\
Std. error (a) & 0.00176976 & 0.00099463 & 0.000697115 & 0.000493205 & 0.000316042 & 0.000331645 & 0.000437113 & 0.000576686 & 0.000927748 & 0.0015146 \\
t-stat (a) & -0.694016 & -0.359108 & -0.417516 & -0.656232 & -0.916719 & -0.358993 & -0.0856523 & -1.74212 & -0.689295 & -1.93683 \\
p-value (a) & 0.488322 & 0.71982 & 0.676662 & 0.512283 & 0.36018 & 0.719906 & 0.931812 & 0.0827266 & 0.491282 & 0.0539021 \\
Beta & 0.984246 & 0.944378 & 0.961525 & 0.970044 & 0.955372 & 0.97976 & 0.967073 & 0.964893 & 0.962656 & 0.946473 \\
SMB & 0.11527 & 0.012178 & 0.00820076 & 0.0329708 & 0.198721 & 0.871312 & 0.000264264 & $1.11917 \mathrm{e}-08$ & $1.59891 \mathrm{e}-15$ & $1.10433 \mathrm{e}-15$ \\
HML & 0.287567 & 0.0214138 & 0.0492737 & 0.00334498 & 0.0087694 & 0.00965342 & 0.226419 & 0.00743056 & 0.00546733 & $6.98231 \mathrm{e}-10$
\end{tabular}




\section{FF 3 factor model (3-months formation period - 3-months holding period)}
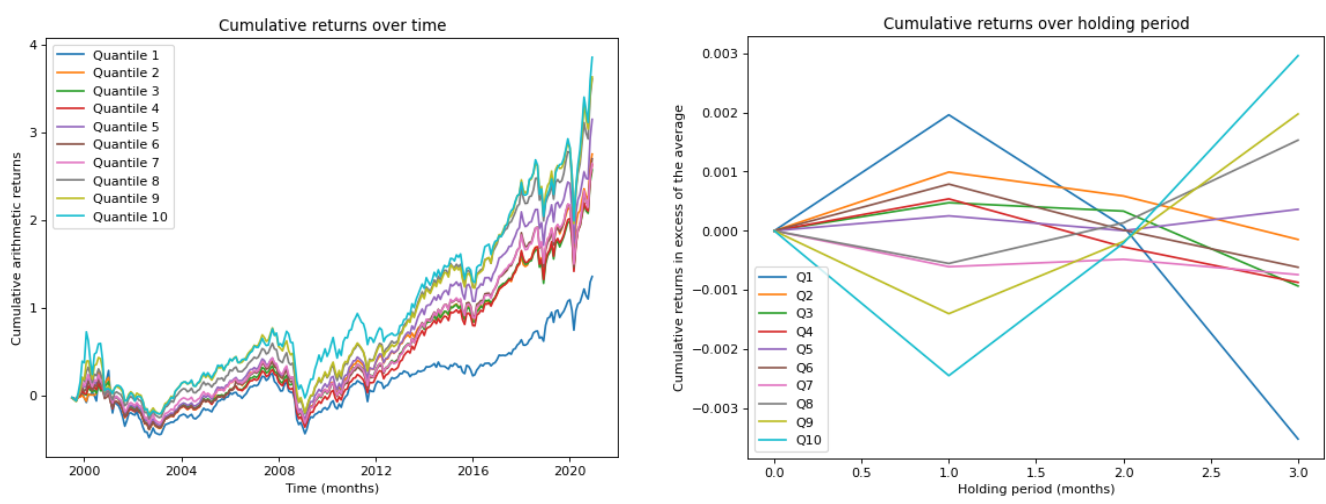

\begin{tabular}{|c|c|c|c|c|c|c|c|c|c|c|}
\hline & Q1 & Q2 & Q3 & Q4 & Q5 & Q6 & Q7 & Q8 & Q9 & Q10 \\
\hline Avg returns & 0.0583165 & 0.0756471 & 0.0715879 & 0.071894 & 0.0782472 & 0.07322 & 0.0725469 & 0.0842542 & 0.0865241 & 0.0915992 \\
\hline Avg excess returns & 0.0352601 & 0.0525907 & 0.0485315 & 0.0488377 & 0.0551908 & 0.0501636 & 0.0494906 & 0.0611978 & 0.0634677 & 0.0685428 \\
\hline Volatility & 0.190193 & 0.167037 & 0.155178 & 0.152202 & 0.153451 & 0.155309 & 0.155272 & 0.159915 & 0.1717 & 0.188232 \\
\hline Sharpe ratio & 0.185391 & 0.314844 & 0.312747 & 0.320874 & 0.359664 & 0.322992 & 0.318734 & 0.382689 & 0.369643 & 0.364139 \\
\hline Alpha & -0.0247032 & -0.00486795 & -0.00763286 & -0.00837056 & -0.00383432 & -0.0096696 & -0.0121897 & -0.00377088 & -0.00689737 & -0.00524287 \\
\hline Std. error ( $\alpha$ ) & 0.00174468 & 0.00116548 & 0.000823085 & 0.000470643 & 0.000456363 & 0.000437841 & 0.000410985 & 0.000570639 & 0.000964186 & 0.00153503 \\
\hline t-stat (a) & -1.17993 & -0.348065 & -0.77279 & -1.48211 & -0.700159 & -1.84039 & -2.47164 & -0.550681 & -0.59613 & -0.284623 \\
\hline$p$-value ( $\alpha$ ) & 0.239133 & 0.728079 & 0.440365 & 0.139549 & 0.484469 & 0.0668769 & 0.0141058 & 0.582336 & 0.551619 & 0.776165 \\
\hline Beta & 1.06922 & 0.997508 & 0.953514 & 0.962359 & 0.962443 & 0.976059 & 0.960192 & 0.956442 & 0.949879 & 0.884134 \\
\hline SMB & 0.00172734 & 0.00332253 & 0.0143229 & 0.000350157 & 0.577348 & 0.392932 & $4.06514 \mathrm{e}-06$ & $3.77464 \mathrm{e}-15$ & $1.44163 \mathrm{e}-19$ & $1.18281 \mathrm{e}-20$ \\
\hline HML & 0.803016 & 0.149324 & 0.0120362 & 0.00277433 & 0.043214 & 0.187703 & 0.00681948 & 0.000402243 & 0.00140724 & $8.98606 \mathrm{e}-10$ \\
\hline
\end{tabular}

\section{FF 3 factor model (3-months formation period - 1-months holding period)}
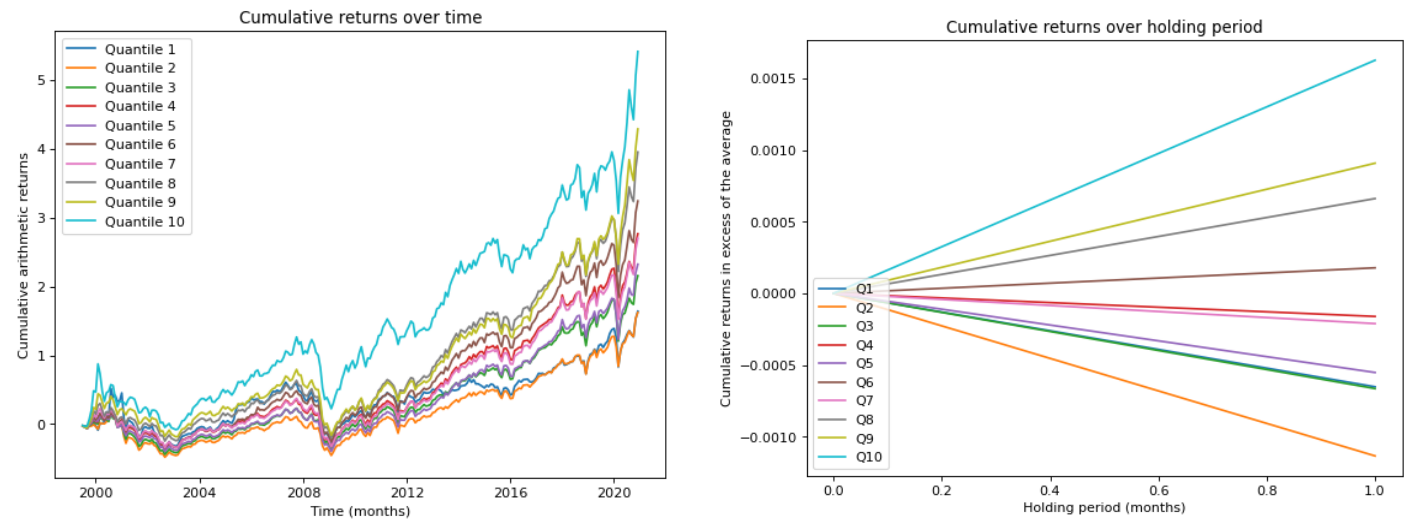

\begin{tabular}{rrrrrrrrrrr} 
& Q1 & Q2 & Q3 & Q4 & Q5 & Q6 & Q7 & Q8 & Q9 & Q10 \\
\hline Avg returns & 0.0663532 & 0.0588106 & 0.0661556 & 0.0740275 & 0.0679116 & 0.0793297 & 0.0732442 & 0.0868866 & 0.0907454 & 0.101975 \\
Avg excess returns & 0.0432968 & 0.0357542 & 0.0430992 & 0.0509712 & 0.0448552 & 0.0562733 & 0.0501879 & 0.0638302 & 0.067689 & 0.0789191 \\
Volatility & 0.206121 & 0.16521 & 0.157798 & 0.15549 & 0.15378 & 0.153922 & 0.155382 & 0.156074 & 0.161217 & 0.17629 \\
Sharpe ratio & 0.210055 & 0.216416 & 0.27313 & 0.32781 & 0.291684 & 0.365596 & 0.322997 & 0.408974 & 0.419862 & 0.447667 \\
Alpha & -0.0231828 & -0.0240432 & -0.0160351 & -0.00815831 & -0.013868 & -0.00359355 & -0.0116291 & 0.000420965 & 0.00218253 & 0.0115764 \\
Std. error (a) & 0.00203164 & 0.00092143 & 0.000609511 & 0.000460834 & 0.000353226 & 0.000427691 & 0.000395812 & 0.000566113 & 0.000886765 & 0.00156353 \\
t-stat (a) & -0.950906 & -2.17444 & -2.19234 & -1.47528 & -3.27175 & -0.700184 & -2.44836 & 0.0619671 & 0.205102 & 0.617003 \\
p-value (a) & 0.342556 & 0.0305953 & 0.0292625 & 0.141376 & 0.00121697 & 0.484453 & 0.0150277 & 0.950638 & 0.837657 & 0.537786 \\
Beta & 1.11035 & 1.01296 & 0.988772 & 0.98092 & 0.976469 & 0.962265 & 0.961738 & 0.930897 & 0.899765 & 0.809634 \\
SMB & 0.201184 & 0.00806137 & 0.00718945 & 0.0109368 & 0.000305185 & 0.308227 & $1.18786 \mathrm{e}-06$ & $2.13953 \mathrm{e}-16$ & $3.084 \mathrm{e}-18$ & $3.85633 \mathrm{e}-18$ \\
HML & 0.283096 & 0.435399 & 0.296608 & 0.00292514 & 0.0361007 & 0.0487336 & 0.0206655 & 0.0511964 & 0.00118614 & $2.95175 \mathrm{e}-06$
\end{tabular}




\section{Appendix 2. Results for additional analysis}

(1) CAPM Model
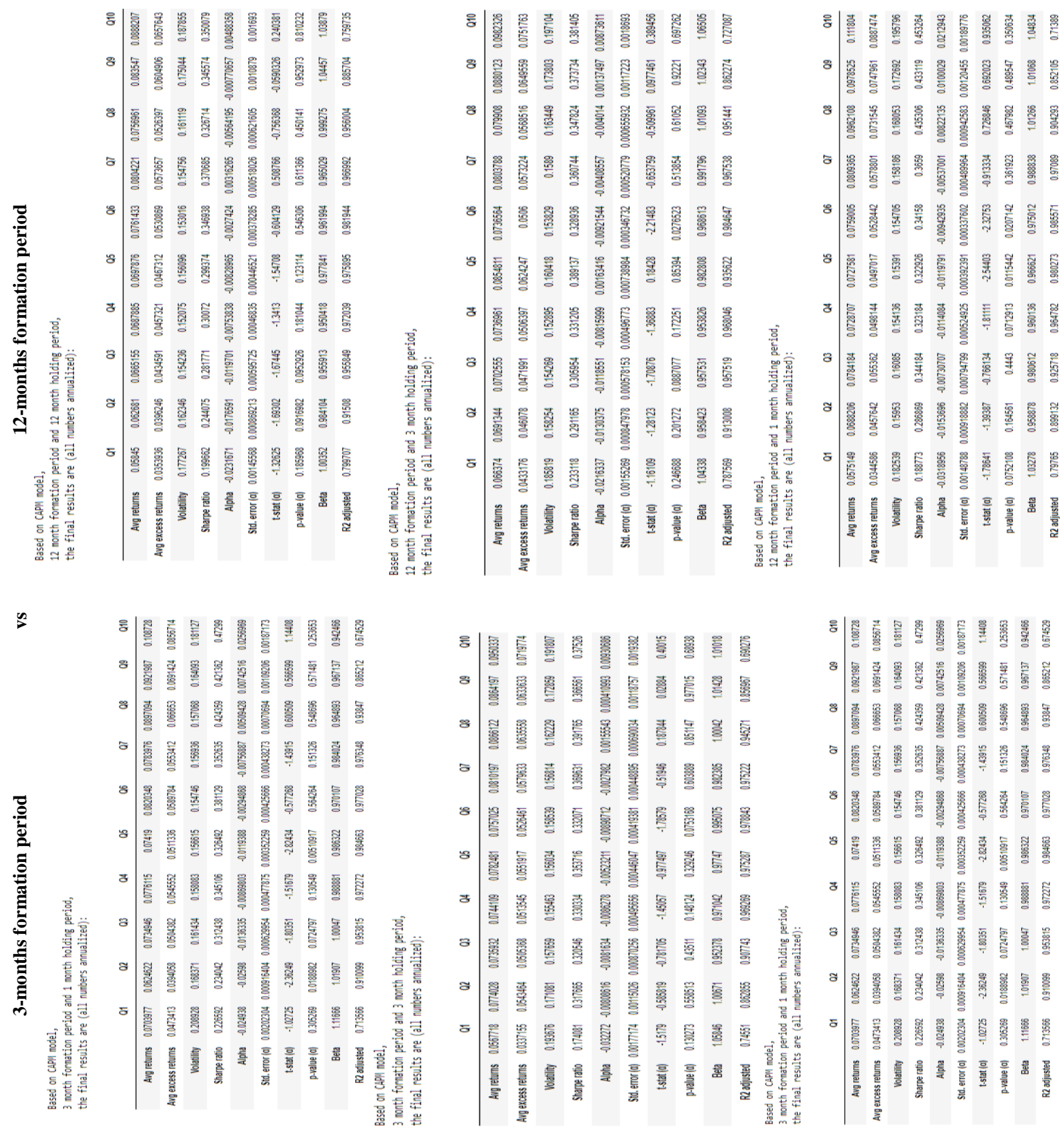

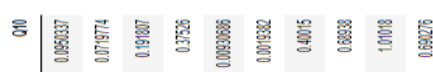

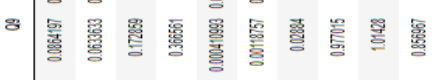

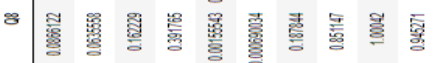

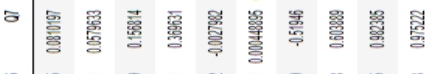

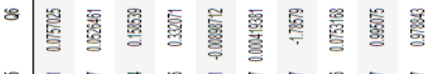

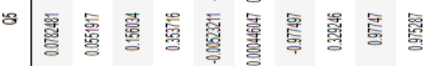

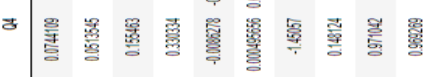

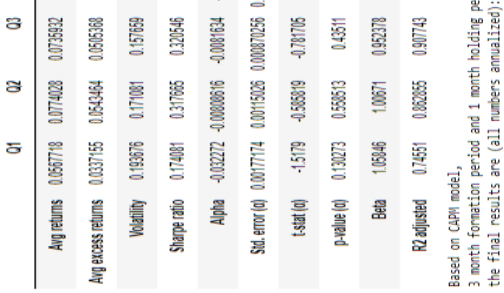

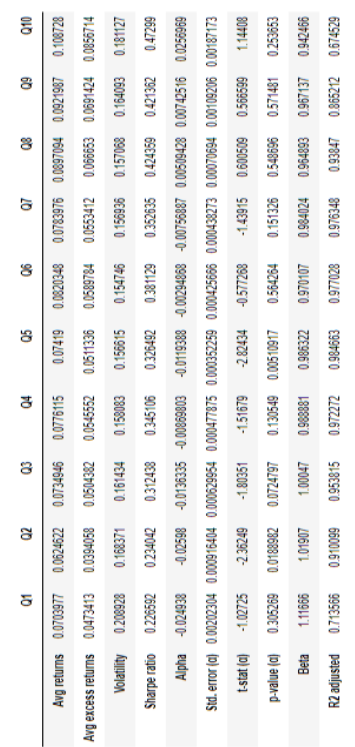


(2) FF-3 factor Model

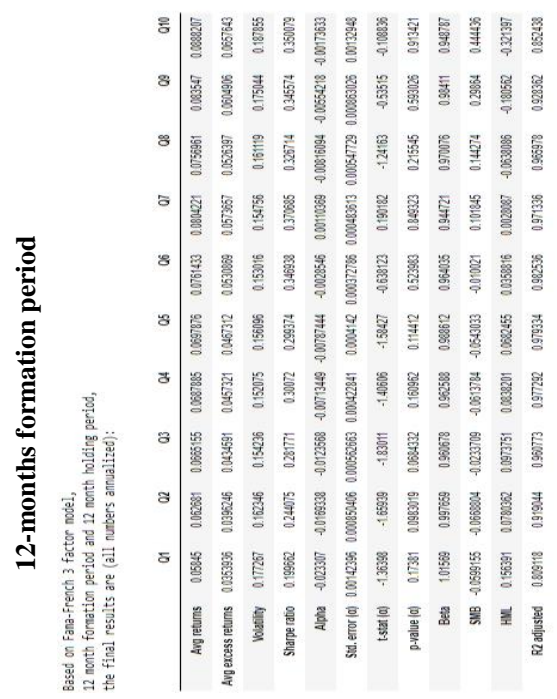

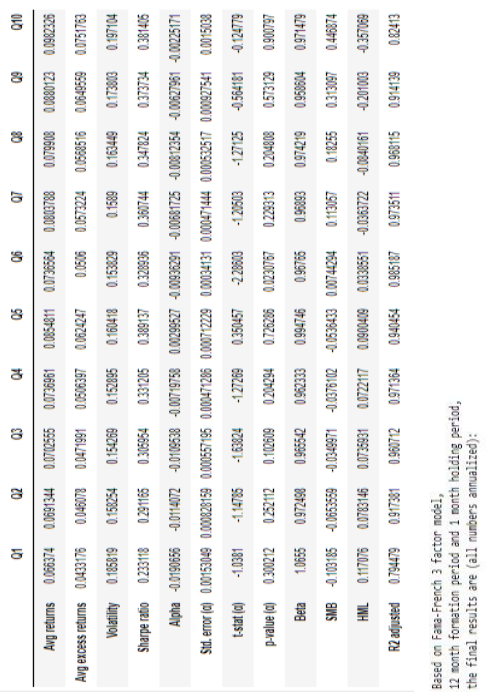

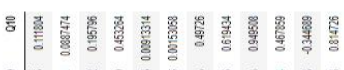

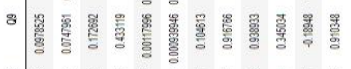

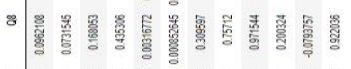

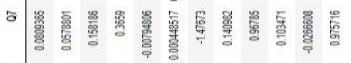

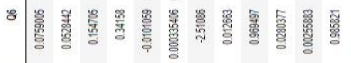

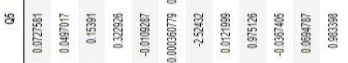

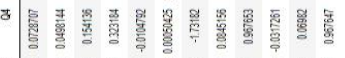

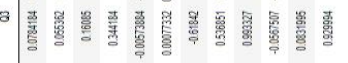

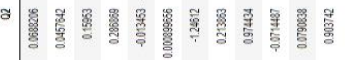

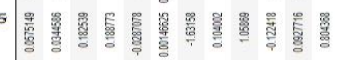

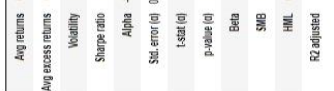

\section{2}

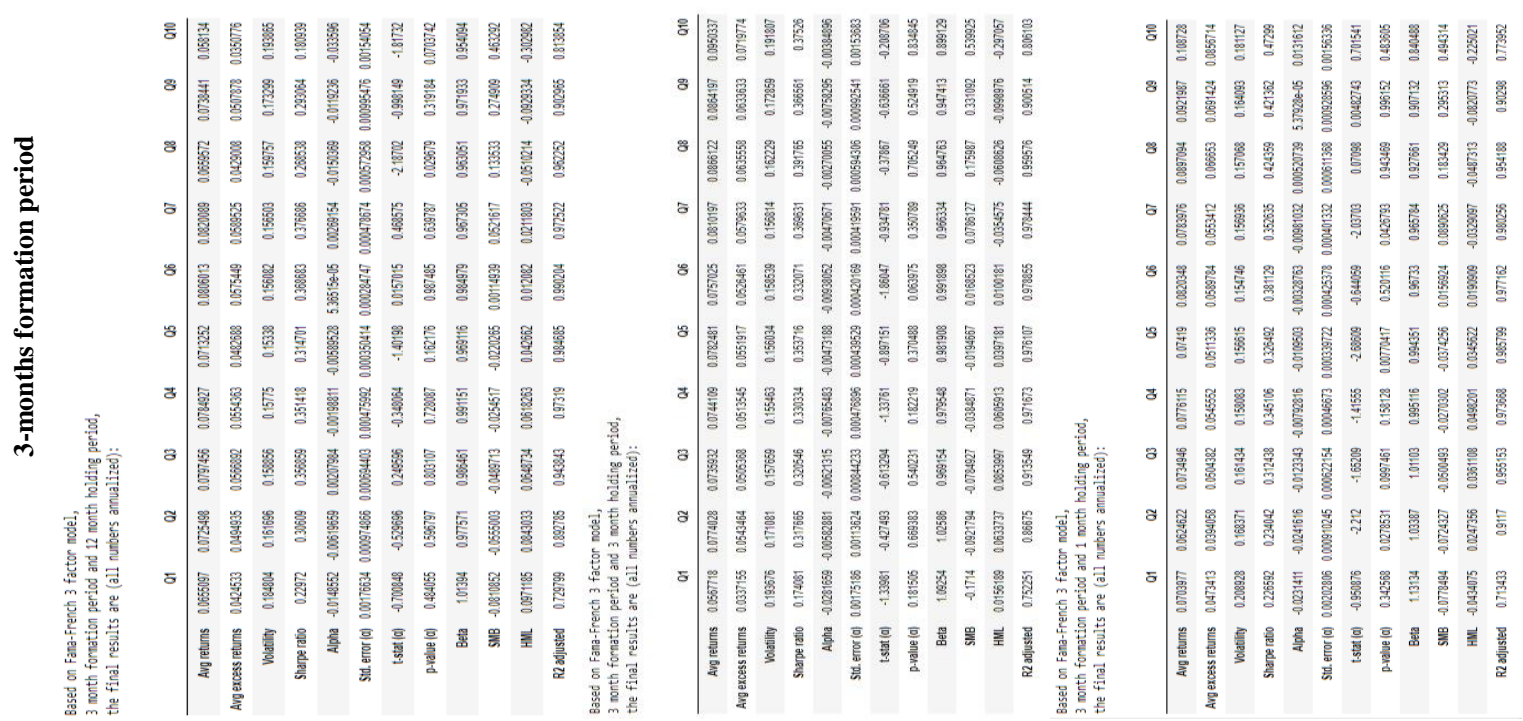


(3) Carhart 4 factor Model

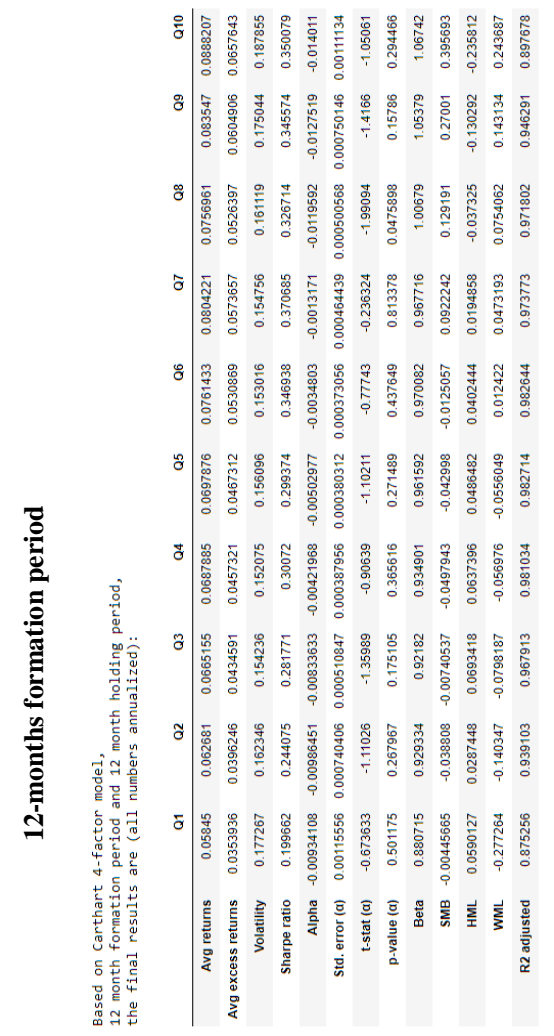

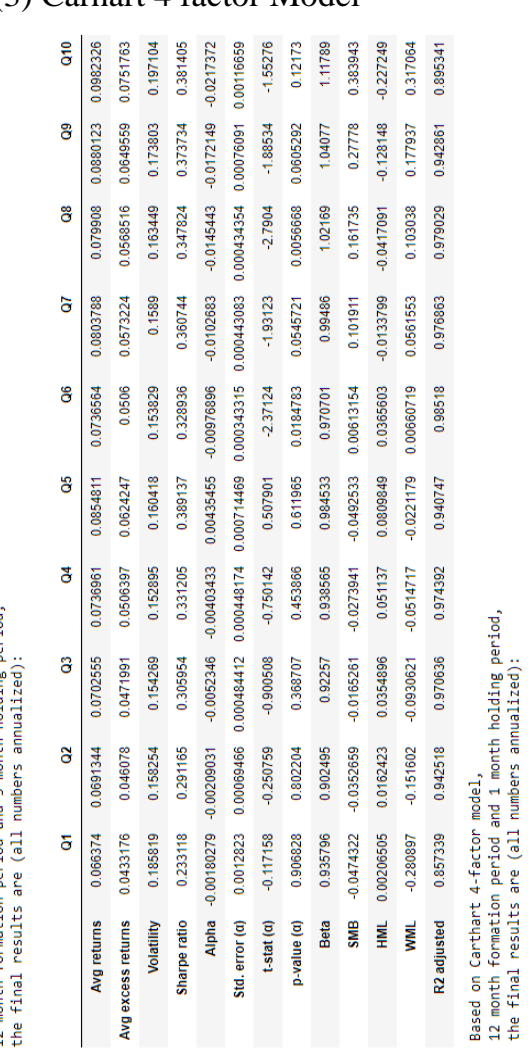

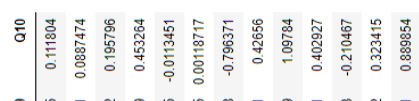

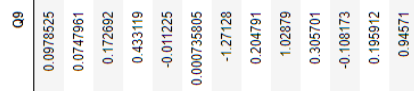

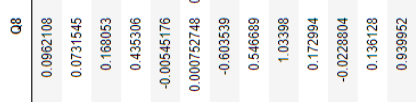

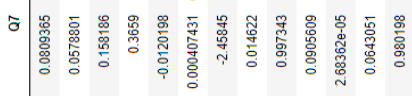

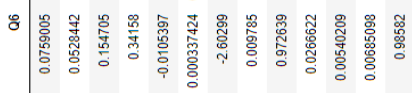

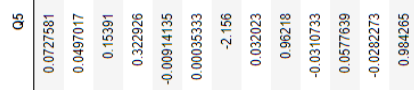

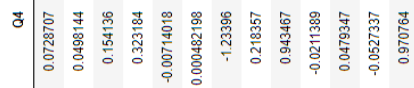

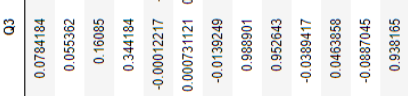

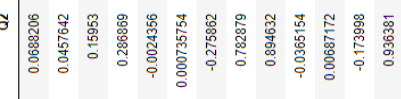

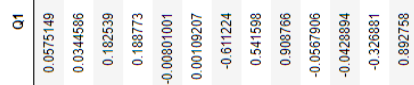

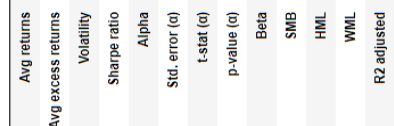

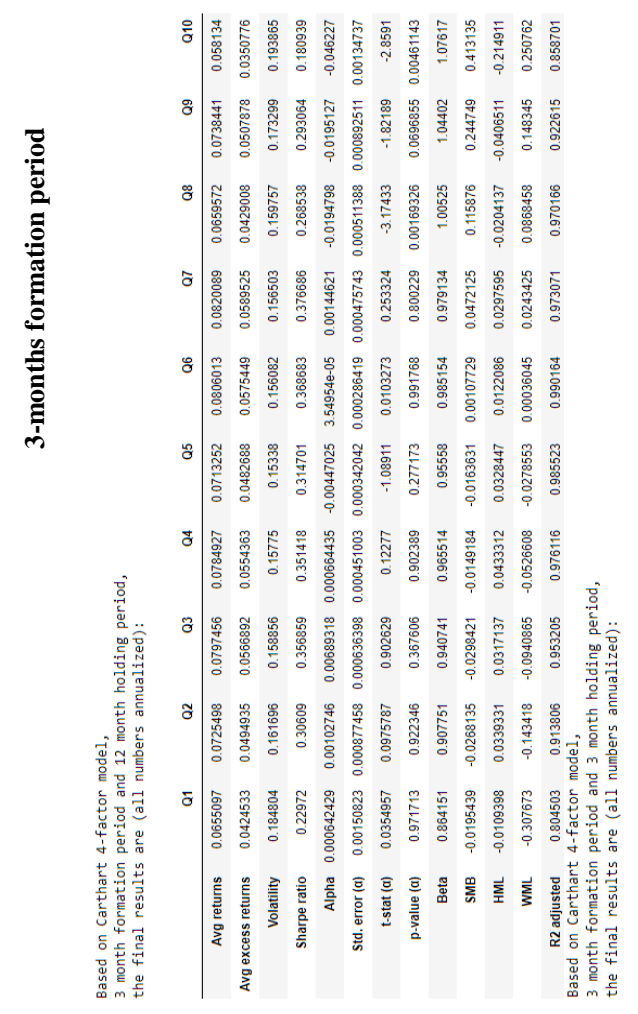

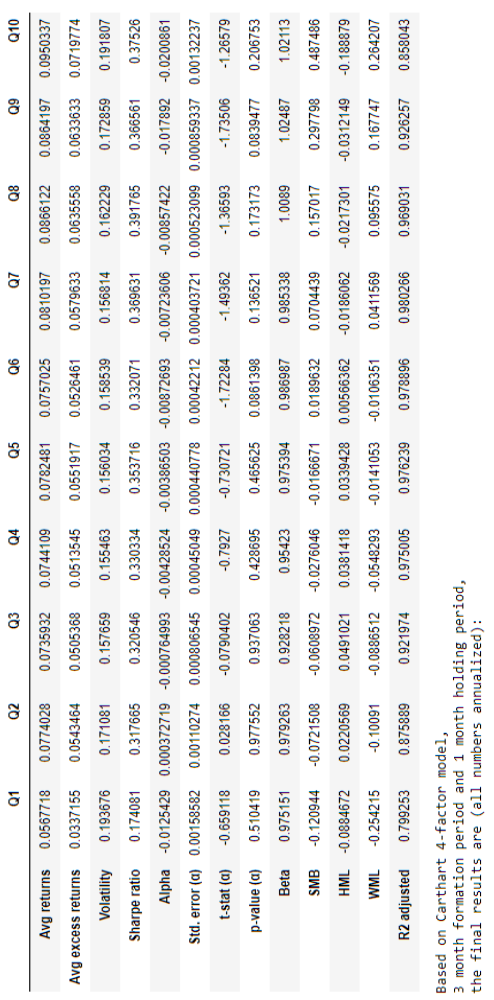

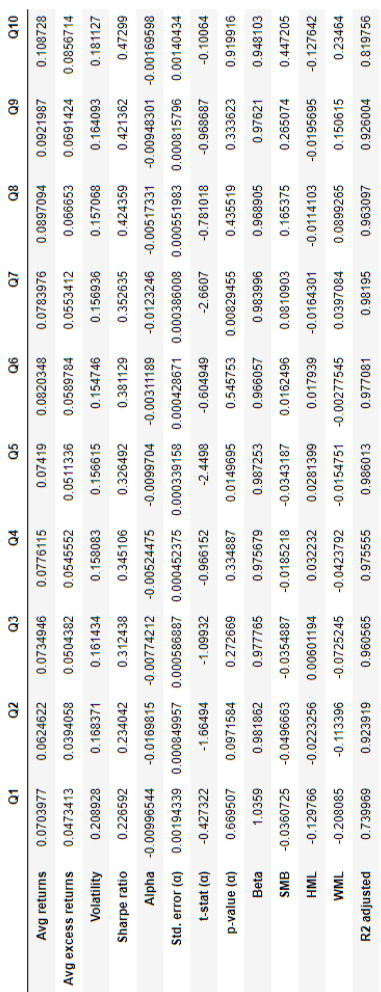


(4) Fama-French 5 factor Model

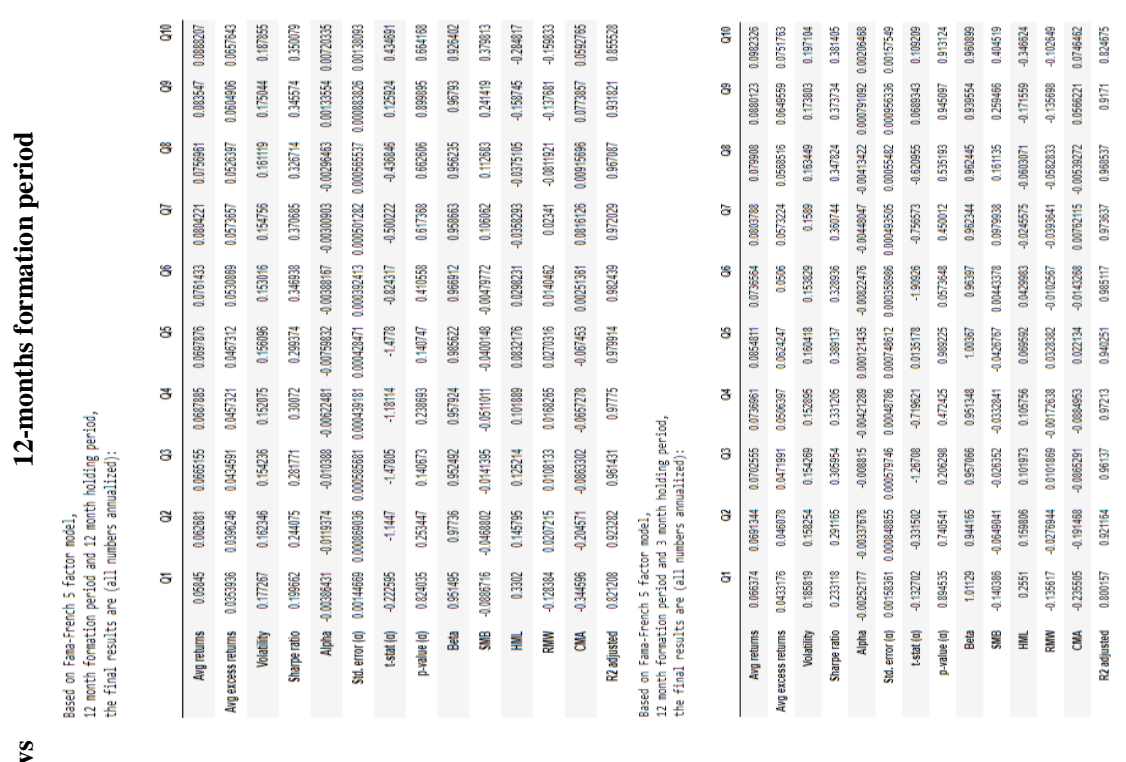

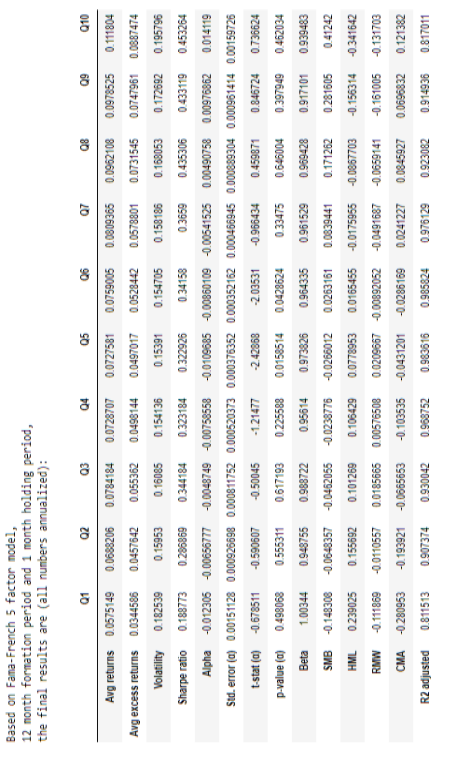

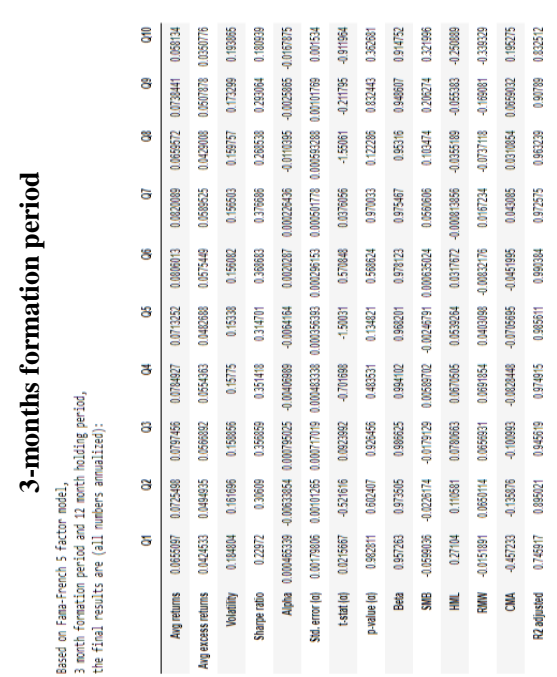

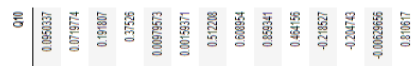

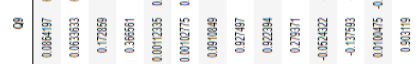

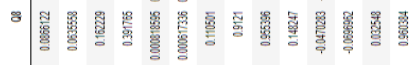

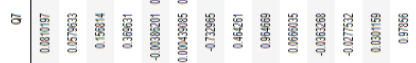

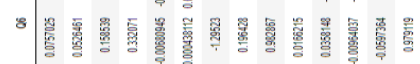

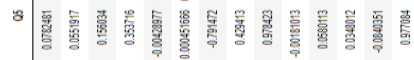

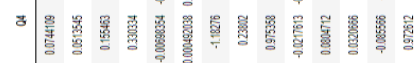

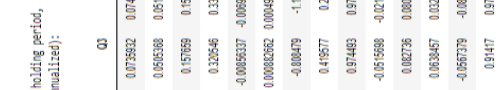

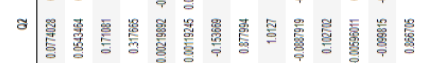

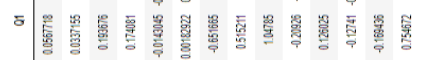

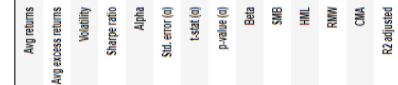

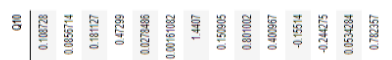

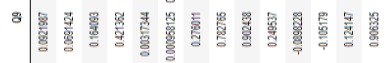

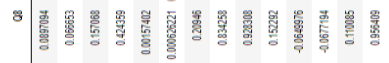

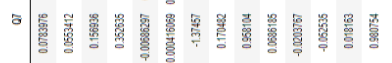

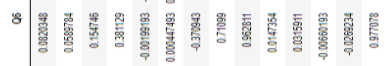

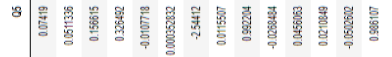

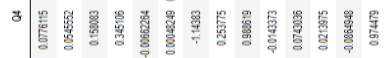

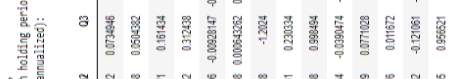

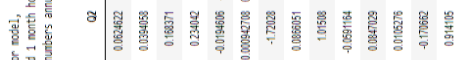

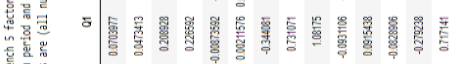

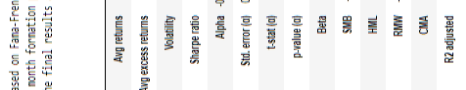


(5) Multi-factor Model

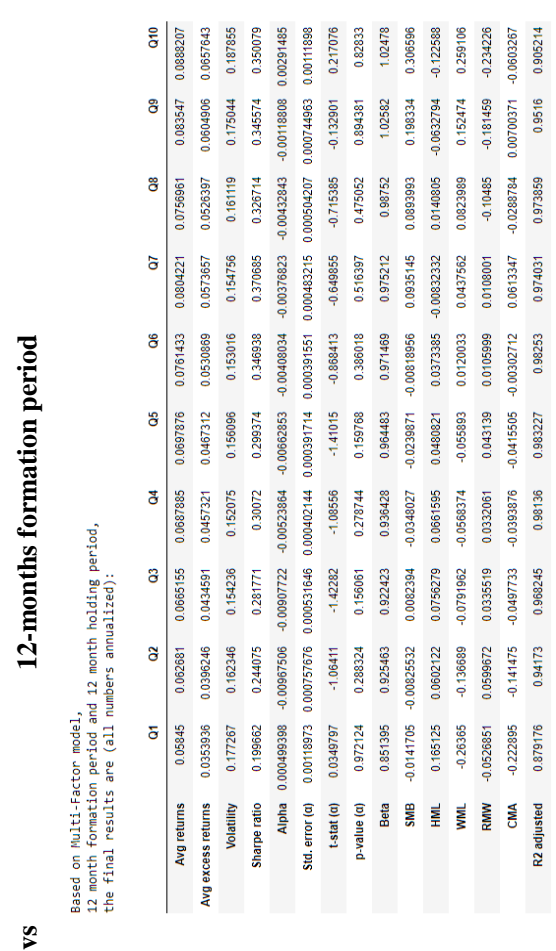

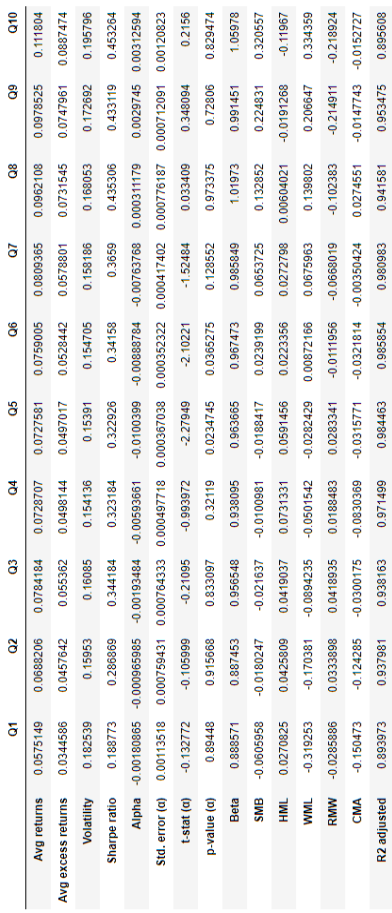

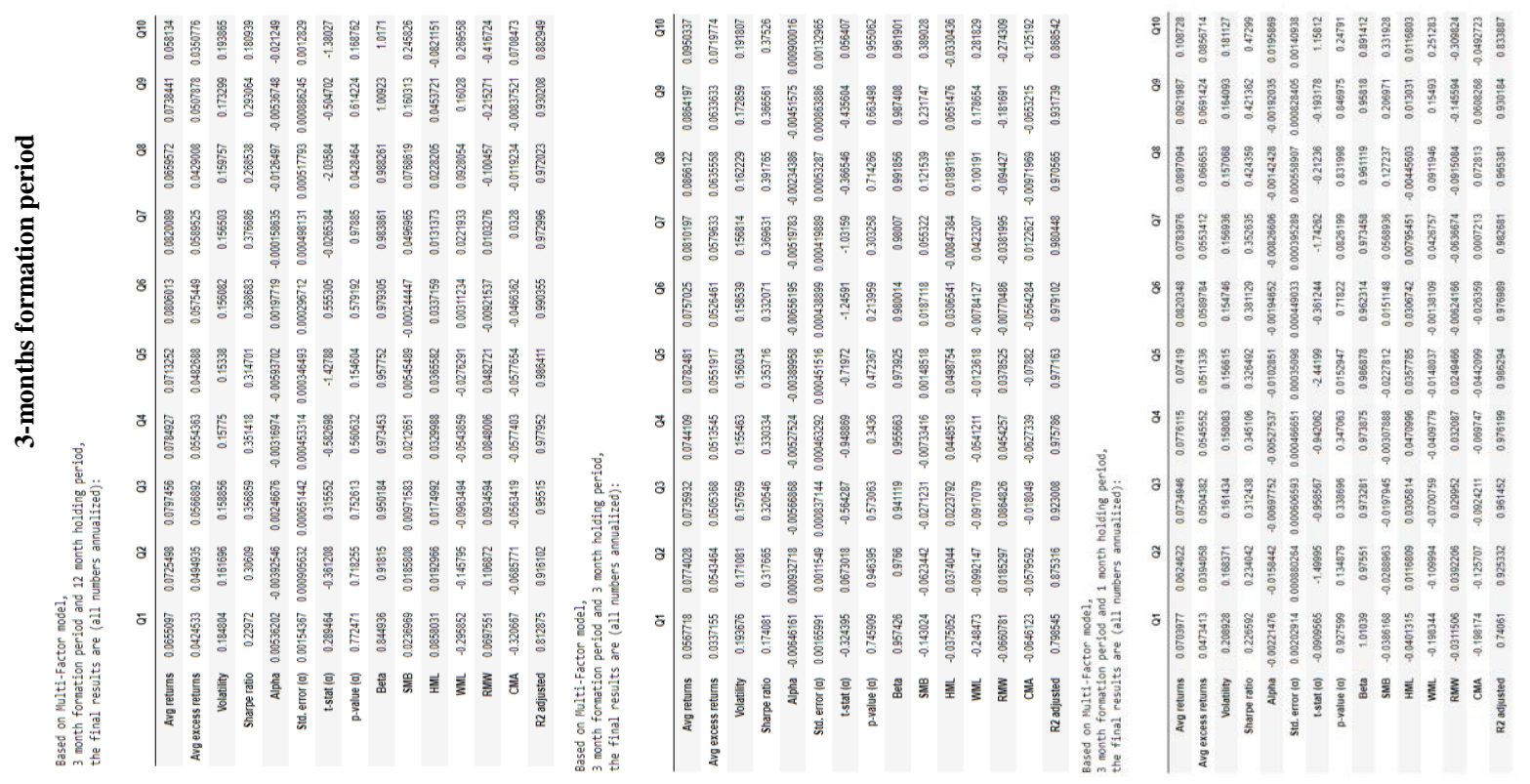

\section{Copyrights}

Copyright for this article is retained by the author(s), with first publication rights granted to the journal.

This is an open-access article distributed under the terms and conditions of the Creative Commons Attribution license (http://creativecommons.org/licenses/by/4.0/). 